\title{
Effects of dietary fatty acids on mitochondrial phospholipid compositions, oxidative status and mitochondrial gene expression of zebrafish at different ages
}

Betancor, M.B. $*^{\dagger}$, Almaida-Pagán, P. F. ${ }^{\dagger}$, Hernández, A., Tocher, D. R.

Institute of Aquaculture, School of Natural Sciences, University of Stirling, Stirling FK9 4LA, Scotland, United Kingdom

Abbreviations: B2M, $\beta$-2-microglobulin; BACT, $\beta$-actin; BHT: butylated hydroxytoluene; cDNA, complementary DNA; CL, cardiolipin; COX, cytochrome c oxidase complex; DHA, docosahexaenoic acid; ETC, electron transport chain; FA, fatty acid; FAME, fatty acid methyl esters; HP-TLC, high performance thin layer chromatography; LA, linoleic acid; LC-PUFA, long chain polyunsaturated fatty acid;MIM, mitochondrial inner membrane; mtDNA, mitochondrial DNA; MUFA, monounsaturated fatty acids; NAC, no-amplification control; ND, NADH-coenzyme Q oxidoreductase complex; NTC, no-template control; OA, oleic acid; PC, phosphatidylcholine, PE, phosphatidylethanolamine; PI, phosphatidylinositol; PIn, peroxidation index; PL, phospholipid; PS, phosphatidylserine; PUFA, polyunsaturated fatty acid;qPCR, quantitative PCR; RO, rapeseed oil; ROS, reactive oxygen species; SFA, saturated fatty acids; SM, sphingomyelin; RT-PCR, real-time PCR; SEM, standar error of the mean; SGR, specific growth rate; SOD, superoxide dismutase;TBARS, thiobarbituric acid reactive substances; TBA, thiobarbituric acid; TCA, trichloroacetic acid; TLC, thin layer chromatography; Tm, melting temperature.

* Corresponding author;

Dr. Mónica B. Betancor, Tel: +44-1786-467993, m.b.betancor@stir.ac.uk

${ }^{\dagger}$ Both authors contributed equally to this work 


\section{Abstract}

Mitochondrial decay is generally associated with impairment in the organelle bioenergetics function and increased oxidative stress, and it appears that deterioration of mitochondrial inner membrane phospholipids (PL) and accumulation of mitochondrial DNA (mtDNA) mutations are among the main mechanisms involved in this process. In the present study, mitochondrial membrane PL compositions, oxidative status (TBARS content and SOD activity) and mtDNA gene expression of muscle and liver were analyzed in zebrafish fed two diets with lipid supplied either by rapeseed oil (RO) or a blend 60:40 of RO and DHA500 TG oil (DHA). Two feeding trials were performed using zebrafish from the same population of two ages (8- and 21-months). Dietary FA composition affected fish growth in 8-month-old animals, which could be related with an increase in stress promoted by diet composition. Lipid peroxidation was considerably higher in mitochondria of 8-month-old zebrafish fed the DHA diet than in animals fed the RO diet. This could indicate higher oxidative damage to mitochondrial lipids, very likely due to increased incorporation of DHA in PL of mitochondrial membranes. Lipids would be among the first molecules affected by mitochondrial reactive oxygen species, and lipid peroxidation could propagate oxidative reactions that would damage other molecules, including mtDNA. Mitochondrial lipid peroxidation and gene expression of 21-month-old fish showed lower responsiveness to diet composition than those of younger fish. Differences found in the effect of diet composition on mitochondrial lipids between the two age groups could be indicating age-related changes in the ability to maintain structural homeostasis of mitochondrial membranes.

Keywords: Diet, fatty acid, mitochondria, zebrafish, oxidative stress, phospholipid. 
Fatty acid (FA) composition of phospholipids (PL) greatly influences both plasma and mitochondrial membranes function (Hulbert et al. 2005). Both the chain length and the number of double bonds in acyl chains have a major influence on the physical properties of the lipids that contain them. Membranes with high levels of polyunsaturated fatty acids (PUFA) are more permeable to ions such as $\mathrm{Na}^{+}, \mathrm{K}^{+}$and $\mathrm{H}^{+}$. This is related to a high metabolic rate as ion pumping constitutes one of the main determinants of this factor (Hulbert et al. 2005). At the same time, membranes with high levels of PUFA are more prone to attack by oxidizing agents and will then participate in free radical reactions that will propagate the oxidative damage throughout the organelle and cell (Pamplona 2011; Zimmiak 2011; Naudi et al. 2013). These processes link membrane lipid composition to animal life span as observed in a wide range of species (Hulbert 2008). In comparative studies performed in various mammals, birds and reptiles, it has been found that species with shorter life span have more unsaturated membranes than species with longer life span (Pamplona et al. 2002; Hulbert et al. 2007).

The mitochondrial free radical theory of aging can still be considered the best explanation for aging and longevity in mammals, birds and multicellular animals in general (Barja 2013). Cell culture studies of invertebrate and mammal models support the fact that reactive oxygen species (ROS), particularly those from mitochondria, play a pivotal role in aging and senescence (Barja 2004; Balaban et al. 2005; Sanz et al. 2006). With age, oxidative stress inside mitochondria increases and oxidation products accumulate resulting in damage to the organelle lipids, protein and DNA. Eventually, this damage has been suggested to lead to mitochondrial dysfunction and, thus, to cell and tissue decay with aging (Shigenaga et al. 1994; Sohal et al. 2002; Paradies et al. 2011). It is known that mitochondrial membranes in mammals have a distinctive composition of lipid classes including PL, glycolipids and cholesterol (Wiseman 1996) related to the role of mitochondria in energy metabolism and oxygen consumption (Hoch 1992). The mitochondrial inner membrane (MIM) is constituted of $80 \%$ proteins (mainly electron transport chain, ETC, components) and $20 \%$ lipids containing a high percentage of the PL class cardiolipin (CL), and essentially no cholesterol (Schlame et al. 2000). CL is a key molecule in mitochondrial function as it participates in the regulation of electron transport and efficiency of oxidative phosphorylation, formation and stability of ETC super-complexes, binding of cytochrome $\mathrm{c}$ to MIM, functioning of MIM enzymes and control of mitochondrial phase apoptosis (Paradies et al. 2002). Moreover, CL 
has a high content of PUFA that, along with its proximity to the site of ROS production, makes it particularly prone to peroxidation. Reduced CL content and/or composition could lead to mitochondrial dysfunction and cell decay. Mitochondrial membranes also contain small amounts of sphingomyelin (SM), which has membrane-rigidifying properties (due to its low content in PUFA) and may retard the lateral propagation of free radicals (Subbaiah et al. 1999; Cutler and Mattson 2011). Other PL species such as phosphatidylserine (PS) and phosphatidylinositol (PI) are also important as they are precursors for signalling molecules, some associated with apoptosis (Hannum and Obeid 1994; Ulmann et al. 2001). In addition, fish mitochondrial activity also appears to be highly modulated by nutritional stressors (Enyu and Shu-Chien 2011) or PUFA levels (Kjaer et al. 2008; Pérez-Sánchez et al. 2013; AlmaidaPagán et al. 2015).

Although lipid peroxidation is quantitatively the main oxidative process inside mitochondria, other organelle molecules are also attacked by ROS and damage to proteins and nucleic acids occur (Sanz et al. 2006). Mitochondrial DNA (mtDNA) is exposed to ROS as it is located close to the site of ROS production. Moreover, mtDNA is not highly condensed or protected by histones, as is nuclear DNA, and its repair activity is limited (Paradies et al. 2011). It has been suggested that mtDNA is also a primary target of ROS and, as more mutations in critical coding regions accumulate, complexes of the ETC become less efficient or inactive, leading to a decline in mitochondrial function (Paradies et al. 2002). Since mtDNA encodes either polypeptides of ETC or components required for their synthesis, mutations in mtDNA will affect the ETC as a whole. ETC-deficient cells are also prone to apoptosis and increased cell loss is therefore a likely important consequence of mitochondrial dysfunction in situations of high oxidative stress (Trifunovic and Larsson 2008). It is important to note that, although the mitochondrial translation machinery is responsible for the synthesis of 13 catalytic proteins of the respiratory chain both in mammals and fish, more than 70 proteins of oxidative phosphorylation are encoded by nuclear DNA, imported from the cytosol and translocated across outer and inner mitochondrial membranes (Ljubicic et al. 2010; Voos 2013). Thus, biogenesis and function of mitochondria requires the encompassing regulation of both mitochondrial and nuclear genomes (Smits et al. 2010).

In summary, mitochondria are among the first responders to various stressors that challenge the homeostasis of cells and organisms (Manoli et al. 2007) and are deeply involved in the aging process. Mitochondrial decay is generally associated with impairment in mitochondrial bioenergetics function and increased oxidative stress (Paradies et al. 2011) and 
it seems clear that deterioration of mitochondrial inner membrane phospholipids, particularly of CL, and accumulation of mtDNA mutations are mechanisms involved in this process. Diet fatty acid composition is one of the main factors modifying plasma and mitochondrial membrane lipid composition (reviewed in Hulbert et al. 2005). Changes in dietary FA composition modify mitochondrial membrane composition and can alter organelle function (Clandinin et al. 1985; Barzanti et al. 1994; Guderley et al. 2008; Martin et al. 2013), which can lead to an imbalance in organelle oxidative status. The aim of the present study was to determine the impact of dietary fatty acid composition on mitochondrial membrane composition and mtDNA gene expression, as possible regulators of the processes associated with mitochondrial decay under situations of high oxidative stress, including aging, in a vertebrate model. Zebrafish (Danio rerio) of two well-differentiated ages were used in order to study the interaction between diet lipid composition and fish age on redox signalling, antioxidant enzyme activities and lipid metabolism.

\section{Materials and methods}

\section{Animals and diets}

The experiment was performed on zebrafish of two different ages ( 8 and 21 months) belonging to a resident colony established in 2009 at the Institute of Aquaculture, University of Stirling (for colony conditions, see Almaida-Pagán et al. 2014). Fish belonging to two different age classes ( 8 or 21 months) each fed on two diets (rapeseed oil and DHA) were used in the present study and the trial carried out in duplicate ( 8 tanks in total). One hundred and twelve zebrafish of $0.21 \pm 0.04 \mathrm{~g}$ ( 8 months) and 32 fish of $0.61 \pm 0.12 \mathrm{~g}$ ( 21 months) were maintained at the same animal density in 30 and 131 aquaria, respectively, containing filtered freshwater which was maintained at a constant temperature of $26 \pm 1{ }^{\circ} \mathrm{C}$ and under a $12 \mathrm{~h}$ light: $12 \mathrm{~h}$ dark photoperiod. The tanks were cleaned daily with approximately one third of the water replaced each day.

Fish were fed four times a day with one of the experimental diets at a ration corresponding to $2 \%$ of the fish wet weight for two months. The experimental diets were prepared in the Institute of Aquaculture. The diets contained $50 \%$ crude protein and $11 \%$ crude lipid and their formulation is shown in Table 1. The dry ingredients were combined and mixed before the addition of the oils (rapeseed oil for the RO diet and a 60:40 blend of 
rapeseed oil and DHA500 TG oil for the DHA diet) and antioxidants and mixing continued for $5 \mathrm{~min}$. Water was added to $30 \%$ of the dry weight to enable pelleting. Pellets of $1.0 \mathrm{~mm}$ were prepared, air dried for $48 \mathrm{~h}$, sieved fines of up $0.5 \mathrm{~mm}$ and stored at $-20{ }^{\circ} \mathrm{C}$ until use. The fatty acid compositions of the diets are shown in Table 2. All diets were formulated to satisfy the nutritional requirements of freshwater fish (NRC, 2011).

After the feeding trial, fish were euthanized by exposure to the anesthetic benzocaine hydrochloride (400 $\mathrm{mg} \mathrm{l}^{-1}$ ) for $10 \mathrm{~min}$ following the cessation of opercular movement and then submerged in chilled water ( 5 parts ice to 1 part water). Whole zebrafish [3 fish per replicate for 8- $(n=6)$ and one fish per replicate for 21-month-old fish $(n=4)$ ], were taken for immediate preparation of mitochondria $(n=4)$ while muscle and liver from individual fish were stabilized in RNAlater ${ }^{\circledR}$ (Life technologies, Paisley, UK) following the manufacturer's instructions and stored at $-20^{\circ} \mathrm{C}$ for molecular analysis $(\mathrm{n}=6$ and 4 for 8 - and 21-month-old fish, respectively). The purified mitochondrial isolates were analysed to determine mitochondrial membrane lipid composition, lipid peroxidation and superoxide dismutase activity. Fish were treated in accordance with British national ethical requirements established by the UK Government Home Office and guidelines determined by the Animals (Scientific Procedures) Act 1986.

\section{Mitochondria isolation}

Approximately, $0.6 \mathrm{~g}$ of fresh (non-frozen) whole fish samples were homogenized in 8-ml ice-cold sucrose buffer (0.4 M phosphate buffer $\mathrm{pH}$ 7.4, 0.25 $\mathrm{M}$ sucrose, $0.15 \mathrm{M} \mathrm{KCl}, 40$ $\mathrm{mM} \mathrm{KF}$, and $1 \mathrm{mM}$ N-acetylcysteine) using a tissue disrupter (IKA T25 digital Ultra-Turrax ${ }^{\circledR}$ Fisher Scientific, Loughborough, UK). Sucrose buffer homogenates were then twice centrifuged at $600 \mathrm{~g}$ for $6 \mathrm{~min}$. After the first centrifugation, the pellet was discarded (cell/nuclei debris) and the supernatant recentrifuged at $600 \mathrm{~g}$. Resulting supernatants were then centrifuged twice at $6,800 \mathrm{~g}$ for $10 \mathrm{~min}$. After the first centrifugation, the pellet was resuspended in sucrose buffer and recentrifuged at 6,800 g. The final pellet was resuspended in $3 \mathrm{ml}$ of $100 \mathrm{mM}$ potassium phosphate buffer $\mathrm{pH} 7.8$, with $0.1 \mathrm{mM}$ EDTA. A $250 \mu 1$ aliquot of each mitochondrial homogenate was frozen in liquid nitrogen and stored at $-80{ }^{\circ} \mathrm{C}$ prior to enzyme activity measurements. The remaining mitochondrial homogenates were subjected directly to lipid extraction. To verify that pellets were highly enriched in mitochondria, portions of the isolates were fixed in $2.5 \%$ glutaraldehyde in $0.1 \mathrm{M}$ cacodylate buffer 
overnight at $4{ }^{\circ} \mathrm{C}$ and then processed prior to analysis by transmission electron microscopy (Tecnai G2 Spirit BioTWIN, FEI Europe, Eindhoven, The Netherlands) as described previously (Almaida-Pagán et al. 2012). Purity of preparations was also tested by measuring total (SOD) and mitochondria-specific (SOD2 or Mn-SOD) superoxide dismutase in the mitochondria isolates (Tocher et al. 2003). SOD2 activity in mitochondria pellets always represented more than $95 \%$ of total superoxide dismutase activity.

\section{Lipid extraction and phospholipid class composition}

Total lipid of mitochondria from whole animal was obtained by solvent extraction basically according to Folch et al. (1957). Briefly, mitochondrial pellets were homogenized in $5 \mathrm{ml}$ of ice-cold chloroform/methanol (2:1, by vol.) containing 0.01 (w/v) butylated hydroxytoluene (BHT) as antioxidant, followed by addition of $1 \mathrm{ml}$ of $0.88 \%(\mathrm{w} / \mathrm{v}) \mathrm{KCl}$, mixing and layers allowed to separate on ice for $1 \mathrm{~h}$. The upper aqueous layer was aspirated and the lower organic layer evaporated under a stream of oxygen-free nitrogen. All lipid extracts were stored at $-20{ }^{\circ} \mathrm{C}$ under a $\mathrm{N}_{2}$ atmosphere prior to analysis.

Phospholipid classes were separated by high-performance thin-layer chromatography (HPTLC) using $10 \times 10 \mathrm{~cm}$ silica gel plates (VWR, Lutterworth, England) and methyl acetate/isopropanol/chloroform/methanol/0.25 \% (w/v) $\mathrm{KCl}(25: 25: 25: 10: 9$, by vol.) as solvent system (Olsen and Henderson 1989). The lipid classes were visualized by charring at $160{ }^{\circ} \mathrm{C}$ for $15 \mathrm{~min}$ after spraying with $3 \%(\mathrm{w} / \mathrm{v})$ aqueous cupric acetate containing $8 \%(\mathrm{v} / \mathrm{v})$ phosphoric acid and quantified by densitometry using a CAMAG-3 TLC scanner (version Firmware 1.14.16) (Henderson and Tocher 1992). Scanned images were recorded automatically and analyzed by computer using winCATS (Planar Chromatography Manager, version 1.2.0).

\section{Phospholipid fatty acid composition}

Individual phospholipid classes from mitochondria were separated by preparativeTLC, using silica gel plates $(20 \times 20 \mathrm{~cm})($ VWR $)$ and the solvent system as above. Individual phospholipid classes were identified by comparison with known standards after spraying with $1 \%(\mathrm{w} / \mathrm{v}) 2^{\prime}, 7^{\prime}$-dichlorofluorescein in $97 \%(\mathrm{v} / \mathrm{v})$ methanol containing $0.05 \%(\mathrm{w} / \mathrm{v}) \mathrm{BHT}$, and 
visualization under UV light (UVGL-58 Minerallight巴 ${ }^{\circledR}$ Lamp, Ultraviolet Prod. Inc., Calif., USA). Each phospholipid class was scraped from the plate into a test tube and subjected directly (on silica) to acid-catalyzed transmethylation at $50{ }^{\circ} \mathrm{C}$ overnight following addition of $2 \mathrm{ml}$ of $1 \%(\mathrm{v} / \mathrm{v})$ sulphuric acid in methanol in order to prepare fatty acid methyl esters (FAME) (Christie 2003). FAME were separated and quantified by gas-liquid chromatography (Carlo Erba Vega 8160, Milan, Italy) using a $30 \mathrm{~m} \times 0.32 \mathrm{~mm}$ i.d. capillary column (CP Wax $52 \mathrm{CB}$, Chrompak, London, UK) and on-column injection at $50^{\circ} \mathrm{C}$. Hydrogen was used as a carrier gas and temperature programing was from $50{ }^{\circ} \mathrm{C}$ to $150{ }^{\circ} \mathrm{C}$ at $40{ }^{\circ} \mathrm{C} \mathrm{min}{ }^{-1}$ and then to $230{ }^{\circ} \mathrm{C}$ at $2.0^{\circ} \mathrm{C} \mathrm{min}^{-1}$. Individual methyl esters were identified by comparison with known standards. Data were collected and processed using Chromcard for Windows (version 1.19).

\section{Measurement of thiobarbituric acid reactive substances (TBARS)}

Approximately $1 \mathrm{mg}$ of total lipid extract from liver mitochondria was used for the measurement of TBARS using an adaptation of the protocol of Burk et al. (1980). Briefly, 50 $\mu 1$ of $0.2 \%(\mathrm{w} / \mathrm{v})$ BHT in ethanol was added to the sample followed by $0.5 \mathrm{ml}$ of $1 \%(\mathrm{w} / \mathrm{v})$ TBA and $0.5 \mathrm{ml} 10 \%(\mathrm{w} / \mathrm{v})$ TCA, both solutions freshly prepared. The reagents were mixed in a stoppered test tube and heated at $100{ }^{\circ} \mathrm{C}$ for $20 \mathrm{~min}$. After cooling, particulate matter was removed from the homogenate by centrifugation at $2000 \mathrm{~g}$, and absorbance in the supernatant determined at $532 \mathrm{~nm}$ against a blank sample. The concentration of TBARS, expressed as ng $\mathrm{g}$ of lipid ${ }^{-1}$, was calculated using the absorption coefficient $0.156 \mu \mathrm{M}^{-1} \mathrm{~cm}^{-1}$.

\section{Superoxide dismutase (SOD) activity}

Total superoxide dismutase (SOD) activity in mitochondrial preparations was assayed by measuring inhibition of oxygen-dependent oxidation of adrenaline (epinephrine) to adenochrome by xanthine oxidase plus xanthine (Panchenko et al. 1975). Plastic semimicrocuvettes containing $0.5 \mathrm{ml}$ of $100 \mathrm{mM}$ potassium phosphate buffer $\mathrm{pH}$ 7.8/0.1 mM EDTA, $200 \mu \mathrm{l}$ adrenaline, $200 \mu \mathrm{l}$ xanthine, and $50 \mu \mathrm{l}$ distilled water (uninhibited control) or $50 \mu \mathrm{l}$ test sample were prepared and the reaction initiated by the addition of $10 \mu \mathrm{xanthine}$ oxidase (Sigma X4875). The reaction was followed at $480 \mathrm{~nm}$ in a spectrophotometer (Uvikon 860, Kontron Instruments, St. Albans, UK) and 1 unit of SOD activity was described as the amount of the enzyme that inhibited the rate of adenochrome production by $50 \%$. The 
percent inhibition of the test sample was correlated with SOD activity using a SOD standard curve (SOD concentration vs. \% Inhibition of the rate of increase of absorbance at $480 \mathrm{~nm}$ ). For mitochondria-specific SOD2, the major isoform in mitochondria, an assay mini-cuvette, was set up as before but, before addition of xanthine oxidase, $50 \mu \mathrm{l}$ of $30 \mathrm{mM} \mathrm{KCN}$ was added to inhibit the cytosolic $\mathrm{Cu} / \mathrm{Zn}-\mathrm{SOD}$ while the mitochondrial Mn-SOD remains unaffected (Marklund 1980).

\section{RNA preparation, $c D N A$ synthesis and quantification}

Total RNA from tissues (muscle and liver) of randomly sampled 8- $(\mathrm{n}=6)$ and 21month-old zebrafish $(n=4)$ was extracted using TRI Reagent (Sigma) according to the manufacturer's protocol. Concentration and purity was determined by electrophoresis and spectrophotometry (Nanodrop ND-1000, Thermo Scientific, Wilmington, USA), followed by purification of the total RNA (RNeasy, Qiagen). Two micrograms of total RNA were reverse transcribed into cDNA using Multiscribe Reverse transcriptase first strand cDNA kit (Applied Biosystems, Foster City, California, USA), following the manufacturer's instructions, using a mixture of random hexamers and anchored oligo-dT. Negative controls (containing no enzyme) were performed to check for genomic DNA contamination.

Information about target genes was retrieved from the mitochondrion genome sequence (Genbank accession number AC024175) and used to design primers for Real-Time PCR (RT-PCR) with Primer3web version 4.0.0 (Untergrasser et al., 2012). Primers were designed to target five mitochondrial genes: COX3, ND3, ND4, ND4L and ND5 (Supplementary Table 1). Their encoding sequence is located between the genes encoding ATP8 and Cytb in the mitochondrial genome, an area shown to be most damaged in human mtDNA with ageing (Schon et al. 2002). Two housekeeping genes were evaluated as internal reference, $\beta$-actin $(\mathrm{BACT})$ and $\beta$-2-microglobulin $(\mathrm{B} 2 \mathrm{M})$, which were chosen as the most stable according to geNorm (Vandesompele et al. 2002).

qPCR was performed using a Biometra TOptical Thermocycler (Analytik Jena, Goettingen, Germany) in 96-well plates in duplicates in $20 \mu$ reaction volumes containing 10 $\mu 1$ of SYBR Green RT-PCR Master Mix (Applied Biosystems, Paisley, UK); $1 \mu 1$ of the primer corresponding to the analyzed gene $(10 \mathrm{pmol}) ; 3 \mu \mathrm{l}$ of molecular biology grade water and $5 \mu \mathrm{l}$ of cDNA, with the exception of the reference genes, which were determined using 2 
$\mu 1$ of cDNA. Amplifications were carried out with a systematic negative control (NTC, notemplate control, containing no cDNA). Standard amplification parameters contained an initial activation step at $95{ }^{\circ} \mathrm{C}$ for $15 \mathrm{~min}$, followed by 35 cycles: $15 \mathrm{~s}$ at $95{ }^{\circ} \mathrm{C}, 30 \mathrm{~s}$ at the annealing $\mathrm{Tm}$ and $30 \mathrm{~s}$ at $72{ }^{\circ} \mathrm{C}$.

\section{Indices and statistical analysis}

The long-chain polyunsaturated fatty acid (LC-PUFA) index corresponds to the sum of fatty acids with 20 or more carbons and 2 or more double bounds. The peroxidation index (PIn) was used as an estimate of PL susceptibility to oxidation and was calculated using the formula: $\mathrm{PIn}=0.025 \times($ percentage of monoenoics $)+1 \times($ percentage of dienoics $)+2 \times$ (percentage of trienoics $)+4 \times($ percentage of tetraenoics $)+6 \times($ percentage of pentaenoics $)+$ $8 \times$ (percentage of hexaenoics) (Witting and Horwitt, 1964). Specific growth rate (SGR \% day $\left.\left.^{-1}\right):\left[\left(\ln \mathrm{W}_{\mathrm{t}}-\ln \mathrm{W}_{\mathrm{i}}\right) / \mathrm{T}\right)\right] \times 100$ where $\mathrm{W}_{\mathrm{t}}=$ mean final weight, $\mathrm{W}_{\mathrm{i}}=$ mean initial weight and $\mathrm{T}=$ total experimental days (Jaya-Ram et al. 2008). Results from mitochondrial lipid analyses, lipid peroxidation (TBARS) and superoxide dismutase (SOD) are presented as mean \pm SEM $(n=4)$. Data were checked for homogeneity of variances by the Levene's test and, where necessary, arc-sin transformed before further statistical analysis. Student t-test analysis was used to assess the differences between groups based on diet and age for each PL class, fatty acid, TBARS content and SOD activity. Interaction between diet and age was analysed by a general linear model. All statistical analyses were performed using SPSS Statistical Software System version 15.0 (SPSS Inc., Chicago, USA). Data from gene expression analysis were presented as mean \pm SEM ( $\mathrm{n}=6$ and 4 for 8- and 21-month-old fish, respectively). Gene expression results were analyzed using the relative expression software tool (REST 2009), which employs a pairwise fixed reallocation randomization test (10,000 randomizations) with efficiency correction (Pfaffl et al. 2002) to determine the statistical significance of expression ratios (gene expression fold changes) between two treatments. Differences were regarded as significant when $p<0.05$.

\section{Results}

Dietary fatty acid composition and fish performance 
The RO diet contained around $8 \%$ saturated fatty acids (SFA), $62 \%$ monounsaturated fatty acids (MUFA), $56 \%$ of which was oleic acid (18:1n-9, OA) and almost $30 \%$ polyunsaturated fatty acids (PUFA), with $19.5 \%$ linoleic acid (18:2n-6, LA) and almost no docosahexaenoic acid (22:6n-3, DHA) (Table 2). The DHA diet contained a lower proportion of monounsaturated fatty acids (46\%) and higher content in polyunsaturated fatty acids, with $19 \%$ as DHA. This was reflected in the diets' peroxidation index (PIn) (60 vs. 218) (Table 2).

No significant mortalities were found for any of the experimental groups and no differences in food intake between groups during the experiment were observed. The 8month-old zebrafish increased in weight during the feeding trial from $0.21 \pm 0.04$ to $0.40 \pm$ $0.07 \mathrm{~g}$ for the RO group and to $0.30 \pm 0.11 \mathrm{~g}$ for the DHA group, while no significant growth was observed in older fish (from $0.61 \pm 0.12$ to $0.69 \pm 0.21 \mathrm{~g}$ for $\mathrm{RO}$ and to $0.54 \pm 0.13 \mathrm{~g}$ for the DHA group). Younger fish fed the RO diet showed a higher specific growth rate (SGR) than those fed the DHA diet $(\mathrm{t}=-3.187 ; p=0.001)$ but there was not difference in SGR between diets in older animals $(\mathrm{t}=-1.550 ; p=0.152)$ (Figure 1). No significant interaction between fish age and diet was observed for SGR $(\mathrm{F}=0.630 ; p=0.432)$.

\section{Effects of age and diet on mitochondrial phospholipid content of whole zebrafish}

The phospholipid contents and class compositions of mitochondria from 8- and 21month-old zebrafish fed the experimental diets are shown in Figure 2. Phosphatidylcholine (PC), phosphatidylethanolamine (PE) and cardiolipin (CL) were the most abundant PL species in all the experimental groups, constituting more than $86 \%$ of total PL in 8-month-old zebrafish and more than $82 \%$ in 21 -month-old fish.

Dietary fatty acid composition affected phospholipid content and composition in whole zebrafish. Total phospholipid content was higher in fish fed the DHA diet than in fish fed the RO diet in both 8 - (72.2 vs. $60.6 \%)(\mathrm{t}=3.076 ; p=0.053)$ and 21 -month-old animals $(61.5$ vs. $48.4 \%)(\mathrm{t}=2.680 ; p=0.037)$ although it was only significant for the older fish. Mitochondria from 8-month-old fish fed the RO diet had less proportions of sphingomyelin $(\mathrm{SM})(\mathrm{t}=2.530 ; p=0.045)$ and phosphatidylserine (PS) $(\mathrm{t}=3.770 ; p=0.009)$ than those fed the DHA diet. In older fish, mitochondria from fish fed the DHA diet had a lower proportion of CL compared to that of fish fed the RO diet (10.5 vs. $12.8 \%)(\mathrm{t}=-4.288 ; p=0.005)$. 
Mitochondria from 8-month-old zebrafish fed the RO diet showed some significant differences in phospholipid composition compared to that of 21-month-old fish, with higher total phospholipid content $(\mathrm{t}=5.229 ; p=0.002)$ and lower proportions of SM $(\mathrm{t}=-4.079 ; p=$ $0.007)$ and PI $(\mathrm{t}=-2.657 ; p=0.0038)$. No significant differences were found between age groups for animals fed the DHA diet. Fish age and dietary fatty acid composition did not show a significant interaction (Age*Diet) on mitochondrial phospholipid content and composition (F values for $\sum$ PL, SM, PC, PS, PI, CL and PE were 0.037, 0.535, 0.027, 0.045, $0.701,0.543$ and 0.052 , respectively; $p$ values are shown in Figure 2).

Effects of age and diet on phospholipid fatty acid compositions of mitochondria of whole zebrafish

There were some significant differences in the fatty acid profiles of mitochondrial PC, $\mathrm{PE}$ and CL from whole zebrafish when the two ages were compared (Tables 3-5). These differences were particularly significant in fish fed the DHA diet. Mitochondrial PC from older fish fed the DHA diet had a lower saturated fatty acid (SFA) content $(\mathrm{t}=6.055 ; p=$ $0.002)$ and higher monounsaturated fatty acids (MUFA) $(\mathrm{t}=-2.934 ; p=0.032)$ (Table 3), PE had higher MUFA $(\mathrm{t}=-12.130 ; p=0.000)$ and lower DHA $(\mathrm{t}=6.909 ; p=0.001)$ and peroxidation index (PIn) $(\mathrm{t}=6.501 ; p=0.001)$ (Table 4), and CL had higher SFA ( $\mathrm{t}=-3.259$; $p=0.047)$ and lower $\mathrm{n}-6$ polyunsaturated fatty acids (PUFA) $(\mathrm{t}=4.343 ; p=0.035)$ (Table 5). Regarding the minor phospholipid classes, PS showed no differences in the main fatty acid groups between age groups (S. Table 2) while PI and SM showed many significant differences, particularly in fish fed the DHA diet, with higher DHA $(\mathrm{t}=-4.883$ and $-4.299 ; p=$ 0.008 and 0.013, respectively) and PIn $(\mathrm{t}=-8.773$ and $-4.486 ; p=0.001$ and 0.011, respectively) in mitochondria of older fish when compared with younger animals (S. Tables 3 and 4). Almost no significant differences were found between age groups in fish fed the RO diet.

Diet composition significantly affected the fatty acid profiles of individual phospholipid species from 8-month-old fish mitochondria and these effects were different for each phospholipid class. The fatty acid composition of PS and SM from mitochondria of 8month-old zebrafish were largely unaffected by diet (S. Tables 2 and 4). The three main phospholipid classes in zebrafish mitochondria responded to dietary fatty acid composition in a similar way. Mitochondria from fish fed the DHA diet had lower levels of n-6 PUFA in PC, 
PE and CL ( $\mathrm{t}=-6.337,-6.065$ and $-7.485 ; p=0.001,0.001$ and 0.002 , respectively), higher DHA $(\mathrm{t}=2.494,8.217$ and $2.619 ; p=0.055,0.000$ and 0.059 , respectively) and total $\mathrm{n}-3$ PUFA content $(\mathrm{t}=3.069,7.895$ and $4.235 ; p=0.028,0.000$ and 0.013 , respectively $)$ and higher PIn value (only significant for PE) $(\mathrm{t}=1.839,5.890$ and $1.314 ; p=0.125,0.001$ and 0.010, respectively) (Tables 3-5). Mitochondrial PI from 8-month-old zebrafish responded differently to dietary fatty acids. Mitochondrial PI from fish fed the DHA diet had lower DHA $(\mathrm{t}=-4.235 ; p=0.013), \mathrm{n}-3$ PUFA $(\mathrm{t}=-3.379 ; p=0.028)$ and PIn $(\mathrm{t}=-4.578 ; p=0.010)$ than PI from fish fed the RO diet (S. Table 3). Mitochondrial CL and PI from fish fed the RO diet had around $16 \%$ more n-6 PUFA than these phospholipid classes in fish fed the DHA diet (Table 5 and S. Table 3) while the RO diet itself had just $4 \%$ more n-6 PUFA than the DHA diet. The DHA diet contained $18 \%$ more DHA than the RO diet but this different DHA content between the two diets was not reflected in the fatty acid composition of any single phospholipid class when the two feeding groups were compared.

When the interaction between fish age and diet (Age*Diet) on fatty acid composition was analyzed, some significant differences were found in specific phospholipid classes, particularly in PE, PI and SM, as indicated by the $P$ values (Tables 4, S. Tables 3 and 4). Almost no significant differences were found for Age*Diet interaction in PC, CL and PS (Tables 3, 5, S. Table 2). PE and PI peroxidation index from 8-month-old fish showed higher susceptibility to diet fatty acid composition than those from 21-month-old fish ( $F=24.359$ and 6.282; $p=0.001$ and 0.031 , respectively). In contrast, CL and SM peroxidation index from older fish showed significant differences between diet groups while no differences were found in younger animals $(\mathrm{F}=3.283$ and $11.587 ; p=0.108$ and 0.009 , respectively).

\section{Lipid peroxidation}

Lipid peroxidation in total lipid of mitochondria from whole zebrafish was estimated by measuring the TBARS contents (Figure 3). In 8-month-old-fish fed the DHA diet, the levels of TBARS were significantly higher than in fish fed the RO diet $(\mathrm{t}=4.123 ; p=0.042)$. No significant differences between dietary groups were found for older animals $(\mathrm{t}=-0.315 ; p=$ 0.782). TBARS content was lower in 21-month-old fish compared to younger fish but it was only significant for fish fed diet DHA $(\mathrm{t}=5.433 ; p=0.048$ for DHA and $\mathrm{t}=2.484 ; p=0.221$ for RO group). The effect of diet fatty acid composition on mitochondrial lipid peroxidation was influenced by age as determined by a general linear model $(\mathrm{F}=9.700 ; p=0.036)$. 
402

403

404

405

406

407

408

409

410

411

412

413

414

415

416

417

418

419

420

421

422

423

424

425

426

427

428

429

430

431

Mitochondrial superoxide dismutase

Mn-SOD or SOD2 represented the main SOD activity in zebrafish mitochondria accounting more than $95 \%$ of total SOD in all the experimental groups. SOD2 activity was higher in fish fed the DHA diet but these differences were not statistically significant in either of the age groups $(\mathrm{t}=1.615$ and $1.697 ; \mathrm{p}=0.304$ and 0.332 for 8 - and 21-month-old fish, respectively) (Figure 4). SOD2 activity remained stable between 8 - and 21-month-old animals $(\mathrm{t}=0.343$ and $-0.537 ; p=0.771$ and 0.656 for $\mathrm{RO}$ and DHA group, respectively) and no interaction between age and diet was found $(\mathrm{F}=0.363 ; p=0.579)$.

\section{Mitochondrial gene expression}

The 8-month-old zebrafish fed the two diets showed significant differences in mitochondrial gene expression in muscle and liver (Figure 5). Muscle from younger fish fed the DHA diet had lower expression of all the analyzed genes, COX3, ND3, ND4, ND4L and ND5, than zebrafish fed the RO diet $(\mathrm{t}=2.387,2.644,4.407,2.625$ and 3.317; $p=0.038$, 0.025, 0.004, 0.03 and 0.008 for COX3, ND3, ND4L, ND4 and ND5, respectively). The same trend was found in 8-month-old fish liver although the differences were only significant for COX3 $(\mathrm{t}=3.099 ; p=0.013)$ and ND3 $(\mathrm{t}=2.570 ; p=0.030)$ (Figure 5). Diet had no significant effect on mitochondrial gene expression in 21-month-old zebrafish. Muscle from 21-monthold zebrafish showed relatively stable mitochondrial gene expression, particularly of ND genes, with no differences between dietary groups. Data from liver of older zebrafish showed a high variation and, although there was a consistent trend of lower mitochondrial gene expression in the DHA group compared to the RO group, the differences were not statistically significant.

When mitochondrial gene expression of muscle from the two age groups was compared, older fish fed the DHA diet showed a higher expression of all the ND genes, although it was only significant for ND3 $(\mathrm{t}=3.180 ; p=0.013)$ and ND5 $(\mathrm{t}=4.965 ; p=0.001)$. Mitochondrial gene expression was found to be higher in liver of 21-month-old zebrafish than in younger fish, particularly for the RO group, these differences being significant for ND3 ( $\mathrm{t}=$ -2.405; $p=0.043)$, ND4L ( $\mathrm{t}=-2.159 ; p=0.049)$ and ND5 $(\mathrm{t}=-2.377 ; p=0.045)$. No interaction between age and diet was found for any of the studied genes in either muscle or liver 
$(\mathrm{F}=1.617,1.175,4.217,1.123$ and 0.806 for muscle COX3, ND3, ND4L, ND4 and ND5, respectively; $\mathrm{F}=0.604,2.165,3.098,0.012$ and 3.636 for liver genes) (see $p$ values for Age*Diet tables in Figure 5).

\section{Discussion}

Dietary fatty acid composition affected fish growth and mitochondrial membrane composition of zebrafish and significantly influenced muscle and liver mitochondrial gene expression and these effects differed with fish age. Zebrafish fed the DHA diet showed lower growth than those fed the RO diet (significant for younger fish) despite being fed the same feed ration ( $2 \% \mathrm{BW}$ per day). This could be related to increased oxidative stress mediated by diet fatty acid composition. Lipid peroxidation in total lipid from mitochondria was double in fish fed the DHA diet than in fish fed the RO diet in 8-month-old fish. This indicated higher oxidative damage to mitochondrial lipids in young zebrafish fed the DHA diet, very likely due to the higher incorporation of long-chain polyunsaturated fatty acids (LC-PUFA), particularly DHA, in phospholipids of mitochondrial membranes in fish fed diet DHA compared to fish fed the RO diet, as shown previously in liver and muscle mitochondria of Atlantic salmon, Salmo salar (Kjaer et al. 2008; Ostbye et al. 2011) and in liver mitochondria of rainbow trout (Almaida-Pagán et al. 2015). Several studies indicated that increase in dietary PUFA elevated the metabolic rate which would be very likely mediated by changes in membrane composition (Hulbert et al. 2005). This conclusion is heavily influenced by recent studies of the metabolic rate of different species and particularly the development of what has been termed the 'membrane pacemaker' theory of metabolism (Hulbert 2008). Polyunsaturation of cell membrane lipids results in more fluid membranes that can promote higher molecular activity of membrane proteins and, in turn, increase the metabolic activity of cells, tissues and, consequently, whole animals (Pamplona et al. 2002; Sanz et al. 2006). At the same time, membranes with increased levels of PUFA are more prone to attack by oxidizing agents and will then participate in long-term, free radical reactions that will propagate oxidative damage throughout the organelle (Hulbert 2005). This theory would explain the huge differences in life span existing among animal species with different levels of unsaturation in their membranes, but could also explain how situations such as thermal or dietary changes in an animal life-cycle could compromise metabolic activity, oxidative stress and tissue function. 
The present data showed that mitochondria from 8-month-old zebrafish fed the DHA diet had higher levels of n-3 LC PUFA and higher peroxidation index (PIn) value in the three main phospholipid classes, phosphatidylcholine (PC), phosphatidylethanolamine (PE) and cardiolipin (CL) (changes in PIn only significant for PE). These data are consistent with those showing considerable dietary modifications of fatty acid composition of mitochondrial phospholipids in rats (Lemieux 2008; Abbott et al. 2010) and fish (Ushio et al. 1997; Robin et al. 2003; Guderley et al. 2008; Ostbye et al. 2011; Martin et al. 2013; Almaida-Pagán et al. 2015). However, they also indicate the existence of regulatory mechanisms of specific fatty acids within mitochondrial membranes as the observed changes did not clearly reflect the dietary compositions. Different mitochondrial phospholipid classes were affected by diet in different ways suggesting the importance of fatty acid composition at the level of specific phospholipids, as suggested for mammals (Carrie et al. 2000; Cha and Jones 2000, Hulbert et al. 2005). Besides, phospholipid fatty acid compositions did not entirely reflect the diet fatty composition. Interestingly, DHA incorporation in the main mitochondrial phospholipids was significantly lower than expected considering the differences in this fatty acid between the experimental diets. This can be in part explained by preferential retention of DHA in fish tissues when this fatty acid is very low in the diet, as found in Atlantic salmon and other fish species (Bell et al. 2004; NRC 2011) and/or increased endogenous synthesis of DHA from linolenic acid (18:3n-3) in zebrafish when dietary levels of n-3 LC-PUFA are reduced (Tocher et al. 2002). This could also be due to the increase in lipid peroxidation observed in 8-month-old zebrafish fed the DHA diet, which could reduce membrane PUFA as found in senescent zebrafish (Almaida-Pagán et al. 2014). The observed increase in SM content in 8month-old zebrafish mitochondria could also suggest higher lipid peroxidation (LucasSánchez et al. 2013; Almaida-Pagán et al. 2014) and may represent an adaptive response in the organelle to mitigate propagation of oxidative reactions through the membrane. On the other hand, high levels of dietary DHA up-regulate uncoupling proteins (UCP), mitochondrial inner membrane transporters that uncouple oxidative phosphorylation, in mammals (Lee et al. 2013). In fish, major changes in UCP mRNA expression have been associated with switches in energy demand and oxidative capacities (Bermejo-Nogales et al. 2010), which may explain the increased oxidation observed in 8-month-old zebrafish.

Assay of mtDNA gene expression showed several differences in muscle and liver between feeding groups for 8-month-old zebrafish. Muscle of young fish fed the DHA diet had lower expression of all the analyzed genes than zebrafish fed the RO diet. The same trend 
was found in liver but differences were only significant for COX3 and ND3. In agreement, sea bream (Sparus aurata) fed on vegetable diets, with low n-3 LC-PUFA contents, exhibited up-regulation of several mitochondrial genes in liver after an environmental stress (PérezSánchez et al. 2013). This could also indicate high oxidative stress inside the mitochondria as the studied genes belong to a specific region of the mitochondrial genome that has been reported to be especially prone to oxidative attack in several tissues of humans and mice (Schon et al. 2002). Genes in this area encode predominantly for subunits of complexes I [NADH-coenzyme Q (CoQ) oxidoreductase] and IV (cytochrome c oxidase) of the electron transport chain (ETC), which appear to be particularly prone to age-related decline in activity in several tissues (Shigenaga et al. 1994; Richter 1995; Trifunovic and Larsson 2008). This is not surprising taking into consideration that 7 out of the 13 mtDNA encoded polypeptides in the ETC are found in complex I while 3 are found in complex IV. Moreover, there is a strong connection between complexes I and IV, and CL. It has been reported that CL is specifically required for electron transfer in complex I of the mitochondrial ETC (Paradies et al. 2002), complex I being considered the main site of ROS production in mitochondria. It is reasonable to suggest that defects in mitochondrial complex I activity in addition to that of complex IV (very tightly bonded to CL), due to oxidation/ depletion of CL molecules and/or mutations affecting the corresponding area in the mitochondrial genome, may increase electron leak from the ETC generating more oxidative stress, mitochondrial damage and, ultimately, mitochondrial dysfunction and bioenergetic decay associated with disease and aging. However, it is acknowledged that a limited number of mitochondrial-encoded genes were evaluated in the present study and that the trend observed may vary among tissues. In this respect, it was recently shown that the regulation of nuclear- and mitochondrial-encoded genes of the respiratory chain is different depending on the tissue metabolic capabilities in teleosts (Bermejo-Nogales et al. 2015).

The effect of dietary fatty acid composition on growth, lipid peroxidation, mitochondrial lipids and gene expression differed between the two age groups. The 21month-old fish showed no significant growth in either feeding group and TBARS content was generally lower than in younger animals, with no differences between dietary groups. In a previous study analyzing changes in mitochondrial lipids during the life-time of zebrafish, we found that zebrafish reached their highest weight around the $18^{\text {th }}$ month of their life-cycle a time during which mitochondrial lipid peroxidation was also at its maximum (Almaida-Pagán et al. 2014). However, fish had a considerably lower weight and TBARS content at the end of 
their life-cycle (24-month-old) indicating that this could be a natural process in zebrafish, regardless of diet. Older zebrafish mitochondrial gene expression was also less affected by the diet fatty acid composition with no differences between feeding groups. This lower responsiveness of lipid peroxidation and mitochondrial gene expression in older fish fed the DHA diet could be due to the fact that younger fish were growing during the feeding trial while older fish were not, resulting in greater incorporation of dietary fatty acids into tissues of young fish. However, this would not fully explain the differences observed in phospholipid fatty acid compositions between age groups. Mitochondrial lipids of 21-month-old zebrafish were affected differently by dietary fatty acid composition than 8-month-old fish. Interestingly, mitochondrial PC and PE from 21-month-old zebrafish showed less difference between the two feeding groups than younger fish, while CL and SM reflected more strongly the DHA diet when compared with the younger fish. Moreover, older fish fed the DHA diet had mitochondria with a significantly lower CL content than those fed the RO diet while no difference was found in younger fish. It is well-known that the aging process involves a reduction in the rate of lipid metabolism and turnover of fatty acids (Hansford and Castro 1982). Therefore, these differences could also indicate age-related changes in the animal's capacity for maintaining the structural homoeostasis of mitochondrial membranes.

In conclusion, the present results suggested there was high oxidative stress in 8month-old zebrafish fed a diet with high DHA. Despite of the existence of mechanisms regulating mitochondrial phospholipid content and phospholipid fatty acid composition, these processes appear to be overridden by the change in dietary fatty acid composition and the main constituents of mitochondrial membranes suffered marked changes in their composition. This situation affected mitochondrial lipid peroxidation, mitochondrial membrane composition and gene expression, and influenced animal growth. Following the membrane pacemaker theory of animal metabolism (Sanz et al. 2006; Hulbert 2007), lipids would be among the first molecules affected by mitochondrial free radicals, and lipid peroxidation could be the propagator of oxidative damage reactions which would attack other organelle molecules, including mtDNA. These changes could affect the organelle function and cell viability by affecting ETC efficiency, ROS production and signalling systems. The effects of dietary fatty acid composition differed between the two age groups, which could be related to observed differences in specific growth rate. Nevertheless, many of the observed changes in phospholipid fatty acid composition with diet in one age group were in the opposite direction in the other age group, or simply remained unchanged which could indicate age-related 
changes in the animal's capacity for maintaining the structural homoeostasis of mitochondrial membranes.

\section{Acknowledgments}

This research and P.F.A.-P. were funded by a Marie Curie Intra-European Fellowship within the $7^{\text {th }}$ Community Framework Programme (PIEF-GA-2011-297964, OLDMITO). The authors report no conflicts of interest.

\section{Compliance with ethical standards}

The authors confirm that there are not potential conflicts of interests. Fish were treated in accordance with British national ethical requirements and the experiments conducted under the UK Government Home Office project Licence number PPL 60/03969 in accordance with the amended Animals Scientific Procedures Act 1986 implementing EU directive 2010/63.

\section{References}

Abbott SK, Else PL, Hulbert AJ (2010) Membrane fatty acid composition of rat skeletal muscle is most responsive to the balance of dietary n-3 and n-6 PUFA. Br J Nutr 103: 522529.

Almaida-Pagán PF, de Costa J, Mendiola P, Tocher DR (2012) Age-related changes in mitochondrial membrane composition of rainbow trout (Oncorhynchus mykiss) heart and brain. Comp Biochem Physiol B 163: 129-137.

Almaida-Pagán PF, Lucas-Sánchez A, Tocher DR (2014) Changes in mitochondrial membrane composition and oxidative status during rapid growth, maturation and aging in zebrafish, Danio rerio. BBA Mol Cell Biol L 1841: 1003-1011.

Almaida-Pagán PF, De Santis C, Rubio-Mejía OL, Tocher DR (2015) Dietary fatty acids affect mitochondrial phospholipid compositions and mitochondrial gene expression of rainbow trout liver at different ages. J Comp Physiol B 185: 73-86. 
590

591

592

593

594

595

596

597

598

599

600

601

602

603

604

605

606

607

608

609

610

611

612

613

614

615

616

617

Balaban RS, Nemoto S, Finkel T (2005) Mitochondria, Oxidants, and Aging. Cell 120: 483495.

Barja G (2004) Free radicals and aging. TRENDS Neurosci. 27: 595-600.

Barja G (2013) Updating the Mitochondrial Free Radical Theory of Aging: An Integrated View, Key Aspects, and Confounding Concepts. Antioxid Redox Signal 19: 1420-1445.

Barzanti V, Battino M, Baracca A, Cavazzoni M, Cocchi M, Noble R, Maranesi M, Turchetto E, Lenaz G (1994) The Effect of Dietary-Lipid Changes on the Fatty-Acid Composition and Function of Liver, Heart and Brain Mitochondria in the Rat at Different Ages. Brit J Nutr: 71, 193-202.

Bell JG, Henderson RJ, Tocher DR, Sargent JR (2004) Replacement of dietary fish oil with increasing levels of linseed oil: modification of flesh fatty acid compositions in Atlantic salmon (Salmo salar) using a fish oil finishing diet. Lipids 39: 223-232.

Bermejo-Nogales A, Calduch-Giner JA, Pérez-Sánchez J (2010) Gene expression survey of mitochondrial uncoupling proteins (UCP1/UCP3) in gilthead sea bream (Sparus aurata L.). J Comp Physiol B 180: 685-694.

Bermejo-Nogales A, Calduch-Giner JA, Pérez-Sánchez J (2015) Unraveling the molecular signatures of oxidative phosphorylation to cope with the nutritionally changing metabolic capabilities of liver and muscle tissues in farmed fish. PLOS One 10: e0122889.

Burk RF, Trumble MJ, Lawrence RA (1980) Rat hepatic cytosolic GSH-dependent enzyme protection against lipid peroxidation in the NADPH microsomal lipid peroxidation system. BBA 618: 35-41.

Carrie I, Clement M, De Javel D, Frances H, Bourre JM (2000) Specific phospholipid fatty acid composition of brain regions in mice: effects of $n-3$ polyunsaturated fatty acid deficiency and phospholipid supplementation. J. Lipid Res 41: 465-472.

Cha MC, Jones PJH (2000) Energy restriction dilutes the changes related to dietary fat type in membrane phospholipid fatty acid composition in rats. Metabolism 49: 977-983.

Christie WW (2003) Lipid analysis: isolation, separation, identification and structural analysis of lipids. Oily Press, Somerset, UK, 2003. 
618 Clandinin MT, Field CJ, Hargraves K, Morson L, Zsigmond E. (1985) Role of diet fat in 619 subcellular structure and function. Can J Physiol Pharm 63: 556.

620 Cutler RG, Mattson MP (2001) Sphingomyelin and ceramide as regulators of development 621 and lifespan. Mech Ageing Dev 122: 895-908.

622 Fang L, Miller YI (2012) Emerging applications for zebrafish as a model organism to study 623 oxidative mechanisms and their roles in inflammation and vascular accumulation of oxidized 624 lipids. Free Radical Biol Med 53: 1411-1420.

625

626

627

628

629

630 631

632

633

634

635

636

637

638

639

640

641

642

643

Folch J, Lees M, Sloane-Stanley GH (1957) A simple method for the isolation and purification of total lipids from animal tissues. J Biol Chem 226: 497-509.

Guderley H, Kraffe E, Bureau W (2008) Dietary fatty acid composition changes mitochondrial phospholipids and oxidative capacities in rainbow trout red muscle, J Comp Physiol B 178: 385-399.

Hannum YA, Obeid LM (1994) Ceramide and the eukaryotic stress response. Biochem Soc Trans 25: 1171-1175.

Hansford RG, Castro F (1982) Age-linked changes in the activity of enzymes of the tricarboxylate cycle and lipid oxidation, and of carnitine content in muscles of the rat. Mech Ageing Dev 19: 191-201.

Henderson RJ, Tocher DR (1992) Thin-layer chromatography, in: Hamilton, R. J., Hamilton, S. (Eds.) Lipid Analysis. A Practical Approach, IRL Press, Oxford, UK, pp. 65-111.

Hoch FL (1992) Cardiolipins and biomembrane function. BBA 1113: 71-133.

Hulbert AJ (2005) On the importance of fatty acid composition of membranes for aging. J Theor Biol 234: 277-288.

Hulbert AJ (2007) Membrane fatty acids as pacemaker of animal metabolism. Lipids 42: 811819.

Hulbert AJ (2008) The links between membrane composition, metabolic rate and lifespan. Comp Biochem Physiol Part A 150: 196-203. 
Hulbert AJ, Turner N, Storlien LH, Else PL (2005) Dietary fats and membrane function: implications for metabolism and disease. Biol Rev 80: 155-169.

Hulbert AJ, Pamplona R, Buffenstein R, Buttemer WA (2007) Life and Death: Metabolic Rate, Membrane Composition, and Life Span of Animals. Physiol Rev 87: 1175-1213.

Jaya-Ram A, Kuah M, Lim P, Kolkovski S, Shu-Chien AC (2008) Influence of dietary HUFA levels on reproductive performance, tissue fatty acid profile and desaturase and elongase mRNAs expression in female zebrafish Danio rerio. Aquaculture 277: 275-281.

Kjaer MA, Todorcevic M, Torstensen B, Vegusdal A, Ruyter B (2008) Dietary n-3 HUFA Affects Mitochondrial Fatty Acid $\beta$-Oxidation Capacity and Susceptibility to Oxidative Stress in Atlantic Salmon. Lipids 43: 813-827.

Lee M-K, Kim I-H, Kim Y (2013) Effects of eicosapentaenoic acid and docosahexaenoic acid on uncoupling protein 3 gene expression in $\mathrm{C}_{2} \mathrm{C}_{12}$ muscle cells. Nutrients 5: 1660-1671.

Lemieux H, Blier PU, Tardif JC (2008) Does membrane fatty acid composition modulate mitochondrial functions and their thermal sensitivity? Comp Biochem Physiol Part A 149: 2029.

Ljubibic V, Joseph A-M, Saleem A, Uguccioni G, Collu-Marchese M, Lai RYJ, Nguyen LM, Hood DA (2010) Transcriptional and post-transcriptional regulation of mitocondrial biogenesis in skeletal muscle: Effects of exercise and aging. BBA Gen Subjects 1800: 223234.

Lucas-Sánchez A, Almaida-Pagán PF, Tocher DR, Mendiola P, de Costa J (2013) Age-related changes in mitochondrial membrane composition of Nothobranchius rachovii. J Gerontol Biol Sci 69: 142-151.

Manoli I, Alesci S, Blackman MR, Sun YA, Rennert OM, Chrousos GP (2007) Mitochondria as key components of the stress response. Trends Endocrin Met 18: 190-198.

Marklund S (1980) Distribution of CuZn superoxide dismutase and Mn superoxide dismutase in human tissues and extracellular fluids. Acta Physiol Scand Suppl 492: 19-23. 
Martin N, Bureau DP, Marty Y, Kraffe E, Guderley H (2013) Dietary lipid quality and mitochondrial membrane composition in trout: responses of membrane enzymes and oxidative capacities. J Comp Physiol B 183: 393-408.

National Research Council (NRC) (2011) Nutrient requirements of fish and shrimp. The National Academies Press, Washington DC.

Naudi A, Jové M, Ayala V, Portero-Ortín M, Barja G, Pamplona R (2013) Membrane lipid unsaturation as physiological adaptation to animal longevity. Front Physiol 4: 1-13.

Olsen RE, Henderson RJ (1989) The rapid analysis of neutral and polar marine lipids using double-development HPTLC and scanning densitometry. J Exp Mar Biol Ecol 129: 189-197.

Ostbye TK, Kjaer MA, Rorá AMB, Torstensen B, Ruyter B (2011) High n-3 HUFA levels in the diet of Atlantic salmon affect muscle and mitochondrial membrane lipids and their susceptibility to oxidative stress. Aquacult Nutr 17: 177-190.

Pamplona R (2011) Advanced lipoxidation end-products. Chem Biol Interact 192: 14-20.

Pamplona R., Barja G, Portero-Otin M (2002) Membrane fatty acid unsaturation, protection against oxidative stress, and maximum life span - a homeoviscous-longevity adaptation? Ann NY Acad Sci 959: 475-490.

Panchenko LF, Brusov OS, Gerasimov M, Loktaeva TD (1975) Intramitochondrial localization and release of rat liver superoxide dismutase. Febs Letters 55: 84-87.

Paradies G, Petrosillo G, Pistolese M, Ruggiero FM (2002) Reactive oxygen species affect mitochondrial electron transport complex I activity through oxidative cardiolipin damage. Gene 286: 135-141.

Paradies G, Petrosillo G, Paradies V, Ruggiero FM (2011) Mitochondrial dysfunction in brain aging: Role of oxidative stress and cardiolipin. Neurochem. Int. 58: 447-457.

Pfaffl MW, Horgan GW, Dempfle L (2002) Relative expression software tool $\left(\mathrm{REST}^{\mathcal{O}}\right.$ ) for group wise comparison and statistical analysis of relative expression results in real-time PCR. Nucleic Acids Res 30: e36. 
696

697

698

699

700

701

702

703

704

705

706

707

708

709

710

711

712

713

714

715

716

717

718

719

720

721

Richter C (1995) Oxidative Damage to Mitochondrial DNA and its relationship to Ageing. Int J Biochem Cell Biol 27: 647-653.

Robin JH, Regost C, Kaushik SJ (2003) Fatty acid profile of fish following a change in dietary fatty acid source: model of fatty acid composition with a dilution hypothesis. Aquaculture 225: 283-293.

Sanz A, Pamplona R, Barja G (2006) Is the mitochondrial free radical theory of aging intact? Antioxid Redox Sign 8: 582-599.

Schlame M, Rua D, Greenberg ML (2000) The biosynthesis and functional role of cardiolipin. Prog Lipid Res 39: 257-288.

Shigenaga MK, Hagen TM, Ames BN (1994) Oxidative damage and mitochondrial decay in aging. Proc Nat Acad Sci US 91: 10771-10778.

Schon EA, Naini A, Shanske S (2002) Identification of mutations in mitochondrial DNA from patients suVering mitochondrial disease. Methods Mol Biol 197: 55-74.

Smits P, Smeitink J, van den Heuvel L (2010) Mitochondrial translation and beyond: processes implicated in combined oxidative phosphorylation deficiencies. J Biomed Biotechnol 737385.

Sohal RS, Mockett RJ, Orr WC (2002) Mechanisms of aging: an appraisal of the oxidative stress hypothesis. Free Radical Bio Med 33: 575-586.

Subbaiah PV, Subramanian VS, Wang K (1999) Novel physiological function of sphingomyelin in plasma. J Biol Chem 274: 36409-36414.

Tocher DR, Agaba M, Hastings N, Bell JG, Dick JR, Teale AJ (2002) Nutritional regulation of hepatocyte fatty acid desaturation and polyunsaturated fatty acid composition in zebrafish (Danio rerio) and tilapia (Oreochromis niloticus). Fish Physiol Biochem 24: 309-320.

Tocher DR, Mourente G, Van der Eecken A, Evjemo JO, Díaz E, Wille M, Bell JG, Olsen Y (2003) Comparative study of antioxidant defence mechanisms in marine fish fed variable levels of oxidised oil and vitamin E. Aquacult Int 11: 195-216. 
Trifunovic A, Larsson NG (2008) Mitochondrial dysfunction as a cause of ageing. J Int Med 263: 167-178.

Ulmann L, Mimouni V, Roux S, Porsolt R, Poisson JP (2001) Brain and hippocampus fatty acid composition in phospholipid classes of aged-relative cognitive deficit rats. Prostag. Leukotr. EES 64: 189-195.

Untergrasser A, Cutcutache I, Koressaar T, Ye J, Faircloth BC, Remm M, Rozen SG (2012) Primer3 p new capabilities and interfaces. Nucleic Acids Res 40: e115.

Ushio H, Muramatsu M, Ohshima T, Koizumi C (1997) Fatty acid compositions of biological membranes from fast skeletal muscle of carp. Fisheries Sci 62: 427-434.

Vandesompele J, De Preter K, Pattyn F, Poppe B, Van Roy N, De Paepe A, Speleman F (2002) Accurate normalization of real-time quantitative RT-PCR data by geometric averaging of multiple internal control genes. Genome Biol doi: 10.1186/gb-2002-3-7-research0034.

Voos W (2013) Chaperone-protease networks in mitochondrial protein homeostasis. BBA Mol Cel Res 1883: 388-399.

Wiseman H (1996) Dietary influences on membrane function: importance in protection against oxidative damage and disease. J Nutr Biochem 7: 2-15.

Witting LA, Horwitt MK (1964) Effect of Degree of Fatty Acid Unsaturation in Tocopherol Deficiency-induced creatinuria. J Nutr 82: 19-33.

Zimmiak P (2011) Relationship of electrophilic stress to aging, Free Radic Biol Med 51: 1087-1105.

\section{Figure legends}

Figure 1. Specific growth rate (SGR \% day $^{-1}$ ) of 8- and 21-month-old zebrafish fed the two experimental diets for two months. Results are means \pm SEM ( $n=56$ for 8 - and $n=16$ for 21-month-old fish). ' + ' symbols represent differences between feeding groups and asterisks denote significant differences between age groups as determined by Student t-test ( $p$ $<0.05)$. 
Figure 2. Phospholipid content (percentage of total lipid weight) and phospholipid class composition (percentage of total phospholipids) of mitochondria isolated from 8- and 21month-old zebrafish fed two different diets. Results are means \pm SEM. $(n=4) . ~ '+'$ symbols represent differences between feeding groups for each phospholipid class as determined by a Student t-test $(p<0.05)$. Asterisks indicate significant differences between age groups for each phospholipid class as determined by a Student t-test $(p<0.05)$. Table represents $P$ values for interaction Diet and Age for each phospholipid class as calculated by a general linear model $(p<0.05)$. CL, cardiolipin; PC, phosphatidylcholine; PE, phosphatidylethanolamine; PI, phosphatidylinositol; PL, phospholipid; $\sum$ PL, total phospholipids; PS, phosphatidylserine; SM, sphingomyelin.

Figure 3. TBARS contents (ng g lipid $^{-1}$ ) of 8- and 21-month-old zebrafish fed the two experimental diets. Data expressed as mean \pm SEM $(n=4)$. ' + ' symbols represent differences between feeding groups and asterisks denote significant differences between age groups as determined by a Student t-test $(p<0.05)$.

Figure 4. Mitochondrial superoxide dismutase (Mn-SOD) activity (units $\mathrm{min}^{-1} \mathrm{mg} \mathrm{prot}^{-1}$ ) of 8- and 21-month-old zebrafish fed the two experimental diets. Data are expressed as mean $\pm \operatorname{SEM}(n=4)$.

Figure 5. Relative expression of COX3, ND3, ND4L, ND4 and ND5 genes of 8- and 21month-old zebrafish fed the two experimental diets. Data are expressed as mean \pm SEM ( $\mathrm{n}$ $=6$ for younger and $\mathrm{n}=4$ for older fish). ' + ' symbols represent differences between feeding groups and asterisks denote significant differences between age groups as determined by a Student t-test $(p<0.05)$. The insert Table presents significant values for the interaction between Age and Diet for each gene as calculated by a general linear model $(p<0.05)$. 
Table 1. Components ( $\mathrm{g} / \mathrm{kg}$ of dry diet) of experimental diets

\begin{tabular}{|c|c|c|}
\hline & RO & DHA \\
\hline \multicolumn{3}{|c|}{$\begin{array}{l}\text { Ingredients of capsules' content ( } g \text { per } 100 \mathrm{~g} d r y \\
\text { weight) }\end{array}$} \\
\hline Vit-free casein ${ }^{1}$ & 480 & 480 \\
\hline Potato Starch ${ }^{2}$ & 150 & 150 \\
\hline Fishmeal $^{3}$ & 50 & 50 \\
\hline Mineral mix ${ }^{4}$ & 47 & 47 \\
\hline Vitamin $\mathrm{mix}^{5}$ & 10 & 10 \\
\hline Arginine & 4 & 4 \\
\hline Leucine & 4 & 4 \\
\hline Methionine & 3 & 3 \\
\hline Cystine & 2 & 2 \\
\hline Orange G & 1 & 1 \\
\hline a-cellulose & 139.6 & 139.6 \\
\hline INCROMEGA DHA 500 TG $^{6}$ & 0 & 44 \\
\hline Rapeseed oil & 110 & 66 \\
\hline Antioxidant $\mathrm{mix}^{8}$ & 0.4 & 0.4 \\
\hline
\end{tabular}

Proximate analysis of the capsules (\% dry matter)

Dry matter 88.8

$\begin{array}{lll}\text { Crude protein } & 49.4 & 49.7\end{array}$

Crude lipid $\quad 11.0 \quad 10.9$

$\begin{array}{lll}\text { NFE } & 33.4 & 33.1\end{array}$

Ash $\quad 6.2 \quad 6.3$

773 Vitamin-free micropulverised (ICN Biomedical Ltd., High Wycombe, UK).

$774{ }^{2}$ Passeli WA4 (Avebe Ltd., Ulceby, South Humberside, UK).

$775{ }^{3}$ Norse-LT94 (Norsidmel AS, Fyllingsdalen, Norway).

$776{ }^{4}$ Supplied (per kg diet): $\mathrm{KH}_{2} \mathrm{PO}_{4}, 22 \mathrm{~g} ; \mathrm{FeSO}_{4} \cdot 7 \mathrm{H}_{2} \mathrm{O}, 1.0 \mathrm{~g} ; \mathrm{ZnSO}_{4} \cdot 7 \mathrm{H}_{2} \mathrm{O}, 0.13 \mathrm{~g} ; \mathrm{MnSO}_{4} \cdot 4 \mathrm{H}_{2} \mathrm{O}$,

$77752.8 \mathrm{mg} ; \mathrm{Cu}-\mathrm{SO}_{4} \cdot 5 \mathrm{H}_{2} \mathrm{O}, 12 \mathrm{mg} ; \mathrm{CoSO}_{4} \cdot 7 \mathrm{H}_{2} \mathrm{O}, 2 \mathrm{mg}$.

$778{ }^{5}$ Supplied (mg kg $\operatorname{diet}^{-1}$ ): ascorbic acid, 1000; myo-inositol, 400; nicotinic acid, 150; calcium

779 pantothenate, 44; allrac- $\alpha$-tocopheryl acetate, 40; riboflavin, 20; pyridoxine hydrochloride, 12;

780 menadione, 10; thiamine hydrochloride, 10; retinyl acetate, 7;3; folic acid, 5; biotin, 1;

781 cholecalciferol, 0.06; cyanocobalamin, 0.02 .

$782{ }^{6}$ CRODA International Plc (East Yorkshire, UK).

$783{ }^{7}$ The Cooperative Food (UK).

$784{ }^{8}$ Dissolved in propylene glycol and contained $\left(\mathrm{g}^{-1}\right)$ : butylated hydroxy anisole, 60; propyl gallate, 60;

785 citric acid, 40.

786 All the other ingredients were obtained from Sigma Chemical Co. Ltd. (Poole, Dorset, UK). 
791 Table 2. Fatty acid composition (\% of total fatty acids) of experimental diets.

\begin{tabular}{|c|c|c|}
\hline & RO & DHA \\
\hline $16: 0$ & 5.1 & 4.2 \\
\hline 18:0 & 1.7 & 2.2 \\
\hline$\sum$ Saturated & 8.2 & 7.9 \\
\hline 18:1n-9 & 55.9 & 39.7 \\
\hline $18: 1 \mathrm{n}-7$ & 3.3 & 2.8 \\
\hline 20:1n-9 & 1.5 & 1.9 \\
\hline$\sum$ Monounsaturated & 62.1 & 46 \\
\hline $18: 2 n-6$ & 19.5 & 13.1 \\
\hline$\sum \mathrm{n}-6$ PUFA & 19.5 & 15.4 \\
\hline $18: 3 n-3$ & 9.3 & 6.3 \\
\hline $20: 5 n-3$ & 0.1 & 3.7 \\
\hline $22: 5 n-3$ & 0 & 1.1 \\
\hline $22: 6 n-3$ & 0.7 & 19 \\
\hline$\sum \mathrm{n}-3$ PUFA & 10.1 & 30.6 \\
\hline$\sum$ PUFA & 29.7 & 46 \\
\hline PIn & 45.9 & 207.7 \\
\hline
\end{tabular}


Table 3. Forward and reverse primers used in gene expression studies.

\begin{tabular}{|c|c|c|c|c|}
\hline Gene & Sequence $\left(5^{\prime} \rightarrow 3^{\prime}\right)$ & Amplicon size (bp) & Efficiency & $\mathrm{T}^{\circ}$ \\
\hline \multirow[t]{2}{*}{ COX3 } & F: AAAGGGTTGCGGTACGGTAT & \multirow[t]{2}{*}{241} & \multirow[t]{2}{*}{0.92} & \multirow[t]{2}{*}{59} \\
\hline & R: TTCGTTCTCCTTCCATGAGG & & & \\
\hline \multirow[t]{2}{*}{ ND3 } & F: CCCGCCTACCATTTTCATT & \multirow[t]{2}{*}{185} & \multirow[t]{2}{*}{0.90} & \multirow[t]{2}{*}{59} \\
\hline & R: TTGGGCTCATTCGTAGGCTAGT & & & \\
\hline \multirow[t]{2}{*}{ ND4 } & F: GATTCAAACCCCCTGAGGAT & \multirow[t]{2}{*}{201} & \multirow[t]{2}{*}{0.91} & \multirow[t]{2}{*}{59} \\
\hline & R: AGTGCTAGGTTGGCCAGATT & & & \\
\hline \multirow[t]{2}{*}{ ND4L } & F: TTCACCGTGTTCACCTCCTA & \multirow[t]{2}{*}{159} & \multirow[t]{2}{*}{0.90} & \multirow[t]{2}{*}{59} \\
\hline & R: CACTTGCTTCACAGGCAGAA & & & \\
\hline \multirow[t]{2}{*}{ ND5 } & F: CACATCTGCACTCACGCTTT & \multirow[t]{2}{*}{177} & \multirow[t]{2}{*}{0.93} & \multirow[t]{2}{*}{59} \\
\hline & R: AAGGAAGGGGGTACCCATAA & & & \\
\hline \multirow[t]{2}{*}{ BACT } & F: CTCTTCCAGCCTTCCTTCCT & \multirow[t]{2}{*}{246} & \multirow[t]{2}{*}{0.99} & \multirow[t]{2}{*}{60} \\
\hline & R: CACCGATCCAGACGGAGTAT & & & \\
\hline \multirow[t]{2}{*}{ B2M } & F: CCACTCCGAAAGTTCATGTGT & \multirow[t]{2}{*}{221} & \multirow[t]{2}{*}{0.97} & \multirow[t]{2}{*}{60} \\
\hline & R: ATCTCCTTTCTCTGGGGTGAA & & & \\
\hline
\end{tabular}

795

796

797 

isolated from whole zebrafish fed with one of two experimental diets.

\begin{tabular}{|c|c|c|c|c|c|}
\hline & \multicolumn{2}{|c|}{ 8-month-old } & \multicolumn{2}{|c|}{ 21-month-old } & \multirow{2}{*}{$\begin{array}{c}\text { Age*Diet } \\
P\end{array}$} \\
\hline & RO & $\mathrm{DHA}$ & RO & $\mathrm{DHA}$ & \\
\hline $16: 0$ & $25.6 \pm 1.6$ & $27.4 \pm 0.5^{*}$ & $25.5 \pm 1.7+$ & $23.2 \pm 0.8$ & 0.012 \\
\hline 18:0 & $6.0 \pm 0.3+$ & $5.5 \pm 0.1$ & $5.9 \pm 0.8$ & $5.4 \pm 0.5$ & 0.887 \\
\hline ¿Saturated & $32.7 \pm 1.5$ & $34.1 \pm 0.6^{*}$ & $32.5 \pm 0.9+$ & $30.5 \pm 0.8$ & 0.012 \\
\hline $18: \ln -9$ & $27.9 \pm 1.3$ & $27.0 \pm 1.4$ & $29.3 \pm 1.7$ & $29.7 \pm 1.5$ & 0.439 \\
\hline $18: 1 n-7$ & $2.1 \pm 0.1^{*}$ & $2.0 \pm 0.2$ & $2.8 \pm 0.3+$ & $2.3 \pm 0.1$ & 0.059 \\
\hline $20: 1 n-9$ & $1.0 \pm 0.3$ & $0.9 \pm 0.2$ & $1.0 \pm 0.2$ & $1.4 \pm 0.3$ & 0.17 \\
\hline $24: 1 n-9$ & $1.2 \pm 0.6$ & $0.9 \pm 0.1^{*}$ & $0.9 \pm 0.3+$ & $2.2 \pm 0.4$ & 0.002 \\
\hline$\sum$ Monounsaturated & $34.0 \pm 1.3$ & $33.3 \pm 2.2^{*}$ & $36.2 \pm 2.3$ & $38.3 \pm 2.3$ & 0.216 \\
\hline $18: 2 n-6$ & $4.0 \pm 0.3+$ & $2.7 \pm 0.1^{*}$ & $4.5 \pm 0.2+$ & $3.1 \pm 0.1$ & 0.809 \\
\hline $20: 2 n-6$ & $0.0 \pm 0.0$ & $0.2 \pm 0.1^{*}$ & $0.5 \pm 0.1+$ & $1.3 \pm 0.3$ & 0.039 \\
\hline $20: 3 n-6$ & $1.4 \pm 0.1+$ & $0.3 \pm 0.1$ & $1.4 \pm 0.3+$ & $0.2 \pm 0.0$ & 0.618 \\
\hline $20: 4 n-6$ & $3.5 \pm 0.4+$ & $1.9 \pm 0.2$ & $3.4 \pm 1.1+$ & $1.7 \pm 0.1$ & 0.849 \\
\hline $22: 5 n-6$ & $0.7 \pm 0.1$ & $0.8 \pm 0.1^{*}$ & $0.7 \pm 0.1+$ & $1.2 \pm 0.2$ & 0.006 \\
\hline$\sum \mathrm{n}-6$ PUFA & $11.3 \pm 1.4+$ & $6.0 \pm 0.3^{*}$ & $11.0 \pm 1.6+$ & $7.7 \pm 0.2$ & 0.111 \\
\hline $20: 5 n-3$ & $2.0 \pm 1.0$ & $2.7 \pm 0.3$ & $2.0 \pm 0.3+$ & $3.3 \pm 0.8$ & 0.465 \\
\hline $22: 6 n-3$ & $18.2 \pm 1.2^{*}$ & $21.7 \pm 2.6$ & $15.7 \pm 1.5$ & $17.8 \pm 1.7$ & 0.429 \\
\hline$\sum \mathrm{n}-3$ PUFA & $21.3 \pm 1.4+$ & $25.6 \pm 2.4$ & $19.2 \pm 1.6$ & $22.2 \pm 2.4$ & 0.553 \\
\hline$\sum$ PUFA & $33.3 \pm 2.1$ & $32.6 \pm 2.6$ & $31.3 \pm 1.7$ & $31.2 \pm 2.4$ & 0.817 \\
\hline$\sum \mathrm{n}-3$ LC-PUFA & $21.0 \pm 1.4+$ & $25.4 \pm 2.3$ & $18.8 \pm 0.3+$ & $21.7 \pm 2.3$ & 0.49 \\
\hline $\mathrm{n} 3 / \mathrm{n} 6$ & $1.9 \pm 0.2+$ & $4.3 \pm 0.2^{*}$ & $1.8 \pm 0.3+$ & $2.9 \pm 0.3$ & 0.001 \\
\hline PIn & $193.4 \pm 10.6$ & $214.8 \pm 20.4$ & $175.7 \pm 12.4$ & $190.5 \pm 17.4$ & 0.684 \\
\hline
\end{tabular}
differences between diet treatments as determined by a t-student $(p<0.05)$. Asterisks denote statistical differences between 8- and 21-month-old zebrafish for each diet group (RO and DHA) when compared using a t-test $(p<0.05)$. Right column represent significance values for the interaction between Diet and Age as indicated by a general linear model $(p<0.05)$. RO, rapeseed oil group; DHA, DHA500 TG oil group; LC-PUFA, long-chain polyunsaturated fatty acids; PIn, peroxidation index; PUFA, polyunsaturated fatty acids. 
Table 5. Fatty acid composition (percentage of total fatty acids) of phosphatidylethanolamine of

mitochondria isolated from whole zebrafish fed with one of two experimental diets.

\begin{tabular}{|c|c|c|c|c|c|}
\hline & \multicolumn{2}{|l|}{ 8-month-old } & \multicolumn{2}{|c|}{ 21-month-old } & \multirow{2}{*}{$\frac{\text { Age*Diet }}{P}$} \\
\hline & RO & DHA & RO & DHA & \\
\hline 16:0 DMA & $1.5 \pm 0.3^{*}$ & $1.5 \pm 0.2$ & $3.1 \pm 0.2+$ & $1.2 \pm 0.5$ & $<0.001$ \\
\hline $16: 0$ & $7.7 \pm 0.7$ & $7.8 \pm 1.0$ & $7.6 \pm 1.2$ & $7.1 \pm 1.6$ & 0.676 \\
\hline 18:0 DMA & $4.1 \pm 1.8$ & $4.5 \pm 1.0$ & $6.6 \pm 0.5+$ & $3.2 \pm 0.2$ & 0.012 \\
\hline 18:0 & $16.3 \pm 1.0$ & $16.1 \pm 0.6$ & $16.0 \pm 0.7$ & $15.7 \pm 1.0$ & 0.863 \\
\hline$\sum$ Saturated & $30.4 \pm 0.9 *$ & $31.9 \pm 0.9$ & $34.0 \pm 1.1$ & $31.0 \pm 2.5$ & 0.014 \\
\hline $16: 1 n-9$ & $1.1 \pm 0.0^{*}$ & $0.5 \pm 0.6^{*}$ & $0.0 \pm 0.0+$ & $3.0 \pm 0.9$ & $<0.001$ \\
\hline 18:1n-9 DMA & $0.7 \pm 0.3^{*}$ & $0.8 \pm 0.1$ & $2.0 \pm 0.8$ & $0.7 \pm 0.3$ & 0.014 \\
\hline $18: 1 n-9$ & $12.8 \pm 0.5+$ & $8.6 \pm 1.3^{*}$ & $13.2 \pm 3.1$ & $17.7 \pm 0.9$ & 0.001 \\
\hline $18: 1 n-7$ & $1.7 \pm 0.1$ & $1.5 \pm 0.1^{*}$ & $2.0 \pm 0.2$ & $2.4 \pm 0.3$ & 0.005 \\
\hline$\sum$ Monounsaturated & $18.3 \pm 1.4+$ & $12.6 \pm 1.2^{*}$ & $20.3 \pm 3.1$ & $25.6 \pm 1.7$ & $<0.001$ \\
\hline $18: 2 n-6$ & $1.7 \pm 0.2+$ & $1.0 \pm 0.1^{*}$ & $1.7 \pm 0.1$ & $1.7 \pm 0.4$ & 0.008 \\
\hline $20: 4 n-6$ & $7.2 \pm 0.8+$ & $4.8 \pm 0.6^{*}$ & $8.3 \pm 1.8+$ & $3.5 \pm 0.6$ & 0.058 \\
\hline $22: 5 n-6$ & $0.9 \pm 0.2+$ & $1.3 \pm 0.1$ & $0.8 \pm 0.0+$ & $1.4 \pm 0.1$ & 0.111 \\
\hline$\sum \mathrm{n}-6$ PUFA & $12.2 \pm 0.9+$ & $7.8 \pm 1.2$ & $13.5 \pm 2.1+$ & $7.8 \pm 0.9$ & 0.377 \\
\hline $20: 5 n-3$ & $0.9 \pm 0.1+$ & $1.9 \pm 0.4$ & $1.3 \pm 0.3$ & $1.5 \pm 0.1$ & 0.017 \\
\hline $22: 5 n-3$ & $0.8 \pm 0.1+$ & $1.3 \pm 0.3$ & $1.4 \pm 0.4$ & $0.8 \pm 0.1$ & 0.034 \\
\hline $22: 6 n-3$ & $33.8 \pm 1.2+$ & $41.6 \pm 1.5^{*}$ & $27.7 \pm 5.2$ & $29.1 \pm 3.3$ & 0.072 \\
\hline$\sum \mathrm{n}-3$ PUFA & $36.0 \pm 1.1+$ & $45.0 \pm 1.9 *$ & $31.3 \pm 6.0$ & $31.9 \pm 3.8$ & 0.049 \\
\hline$\sum$ PUFA & $51.2 \pm 2.0$ & $55.4 \pm 1.7^{*}$ & $45.7 \pm 3.9$ & $43.4 \pm 3.3$ & 0.05 \\
\hline$\sum \mathrm{n}-3$ LC-PUFA & $35.6 \pm 1.2+$ & $44.8 \pm 2.0^{*}$ & $30.7 \pm 6.0$ & $31.4 \pm 3.1$ & 0.048 \\
\hline $\mathrm{n} 3 / \mathrm{n} 6$ & $3.0 \pm 0.3+$ & $5.8 \pm 0.7^{*}$ & $2.4 \pm 0.9$ & $4.1 \pm 0.7$ & 0.149 \\
\hline PIn & $330.6 \pm 11.8+$ & $386.8 \pm 15.0 *$ & $289.8 \pm 38.2$ & $269.9 \pm 33.5$ & 0.031 \\
\hline
\end{tabular}

811

812

813

814

815

816

817

818

819

Data expressed as mean \pm SD $(n=4)$. ' + ' symbols within a row and for each age group represent significant differences between diet treatments as determined by a t-student $(p<0.05)$.

Asterisks denote statistical differences between 8- and 21-month-old zebrafish for each diet group ( $\mathrm{RO}$ and $\mathrm{DHA}$ ) when compared using a t-test $(p<0.05)$. Right column represent significance values for the interaction between Diet and Age as indicated by a general linear model $(p<0.05)$. DMA, dimethyl acetal; RO, rapeseed oil group; DHA, DHA500 TG oil group; LC-PUFA, I ong-chain polyunsaturated fatty acids; PIn, peroxidation index; PUFA, polyunsaturated fatty acids. Fatty acids representing less than $1 \%$ of total fatty acids are not shown. 

from whole zebrafish fed with one of two experimental diets.

\begin{tabular}{|c|c|c|c|c|c|}
\hline & \multicolumn{2}{|c|}{ 8-month-old } & \multicolumn{2}{|c|}{ 21-month-old } & \multirow{2}{*}{$\frac{\text { Age*Diet }}{P}$} \\
\hline & RO & $\mathrm{DHA}$ & RO & DHA & \\
\hline 16:0 & $5.7 \pm 0.5$ & $7.8 \pm 1.7$ & $7.4 \pm 2.3$ & $8.3 \pm 0.5$ & 0.542 \\
\hline 18:0 & $2.3 \pm 0.1+^{*}$ & $4.6 \pm 1.3^{*}$ & $5.1 \pm 1.3+$ & $10.4 \pm 0.5$ & 0.043 \\
\hline$\sum$ Saturated & $9.0 \pm 0.1+*$ & $14.0 \pm 2.9 *$ & $14.0 \pm 3.4+$ & $21.6 \pm 1.6$ & 0.421 \\
\hline $16: 1 n-7$ & $1.6 \pm 0.8$ & $2.7 \pm 0.8$ & $3.4 \pm 1.2$ & $3.6 \pm 1.5$ & 0.472 \\
\hline $18: 1 \mathrm{n}-9$ & $16.1 \pm 0.9$ & $17.5 \pm 0.6$ & $19.6 \pm 4.5$ & $14.9 \pm 1.9$ & 0.12 \\
\hline $18: 1 \mathrm{n}-7$ & $9.7 \pm 0.7$ & $11.8 \pm 1.8$ & $8.0 \pm 1.9$ & $11.6 \pm 3.4$ & 0.521 \\
\hline 20:1n-9 & $1.8 \pm 0.4$ & $2.7 \pm 1.0$ & $1.3 \pm 0.5$ & $1.7 \pm 0.1$ & 0.647 \\
\hline$\sum$ Monounsaturated & $30.1 \pm 2.2+$ & $37.5 \pm 3.3$ & $34.4 \pm 5.0$ & $32.7 \pm 0.3$ & 0.072 \\
\hline $18: 2 n-6$ & $26.9 \pm 2.4+$ & $18.0 \pm 2.8^{*}$ & $22.8 \pm 4.7+$ & $11.0 \pm 0.4$ & 0.494 \\
\hline $20: 2 n-6$ & $2.1 \pm 0.3$ & $1.9 \pm 0.2$ & $1.8 \pm 0.7$ & $1.9 \pm 0.7$ & 0.618 \\
\hline $20: 3 n-6$ & $7.6 \pm 1.2+$ & $1.6 \pm 0.4$ & $5.9 \pm 2.9$ & $0.6 \pm 0.3$ & 0.77 \\
\hline $20: 4 n-6$ & $2.8 \pm 0.8$ & $1.9 \pm 0.5$ & $2.2 \pm 0.6$ & $2.7 \pm 0.4$ & 0.09 \\
\hline$\sum$ n-6 PUFA & $40.1 \pm 2.4+$ & $24.3 \pm 2.7^{*}$ & $33.8 \pm 7.0+$ & $18.3 \pm 2.0$ & 0.239 \\
\hline $18: 3 n-3$ & $2.9 \pm 0.5$ & $3.1 \pm 0.6$ & $2.6 \pm 0.5$ & $1.6 \pm 0.2$ & 0.153 \\
\hline $20: 3 n-3$ & $1.0 \pm 0.1$ & $1.4 \pm 0.3$ & $0.9 \pm 0.2$ & $0.9 \pm 0.1$ & 0.289 \\
\hline $20: 5 n-3$ & $0.9 \pm 0.1+*$ & $1.7 \pm 0.3$ & $1.3 \pm 0.2$ & $1.7 \pm 0.1$ & 0.209 \\
\hline $22: 6 n-3$ & $11.1 \pm 2.2+$ & $15.6 \pm 2.0$ & $10.2 \pm 2.8+$ & $20.3 \pm 3.6$ & 0.103 \\
\hline$\sum \mathrm{n}-3$ PUFA & $16.7 \pm 1.8+$ & $23.1 \pm 1.9$ & $16.3 \pm 3.5+$ & $25.7 \pm 3.3$ & 0.409 \\
\hline$\sum$ PUFA & $61.0 \pm 2.1+$ & $48.5 \pm 4.5$ & $51.6 \pm 8.0$ & $45.8 \pm 1.9$ & 0.35 \\
\hline ¿n-3 LC-PUFA & $13.8 \pm 2.3+$ & $19.9 \pm 1.8$ & $13.4 \pm 3.0+$ & $23.8 \pm 3.3$ & 0.212 \\
\hline $\mathrm{n} 3 / \mathrm{n} 6$ & $0.4 \pm 0.1+$ & $1.0 \pm 0.1$ & $0.5 \pm 0.1+$ & $1.4 \pm 0.3$ & 0.031 \\
\hline PIn & $170.2 \pm 17.8$ & $189.8 \pm 18.7$ & $156.3 \pm 26.0+$ & $223.5 \pm 23.0$ & 0.108 \\
\hline
\end{tabular}

Data expressed as mean \pm SD $(n=4)$. ' + ' symbols within a row and for each age group represent significant differences between diet treatments as determined by a t-student $(p<0.05)$. Asterisks denote statistical differences between 8- and 21-month-old zebrafish for each diet group (RO and DHA) when compared using a t-test $(p<0.05)$. Right column represent significance values for the interaction between Diet and Age as indicated by a general linear model $(p<0.05)$. RO, rapeseed oil group; DHA, DHA500 TG oil group; LC-PUFA, long-chain polyunsaturated fatty acids; PIn, peroxidation index; PUFA, polyunsaturated fatty acids. Fatty acids representing less than $1 \%$ of total fatty acids are not shown. 
$830 \quad$ Fig.1

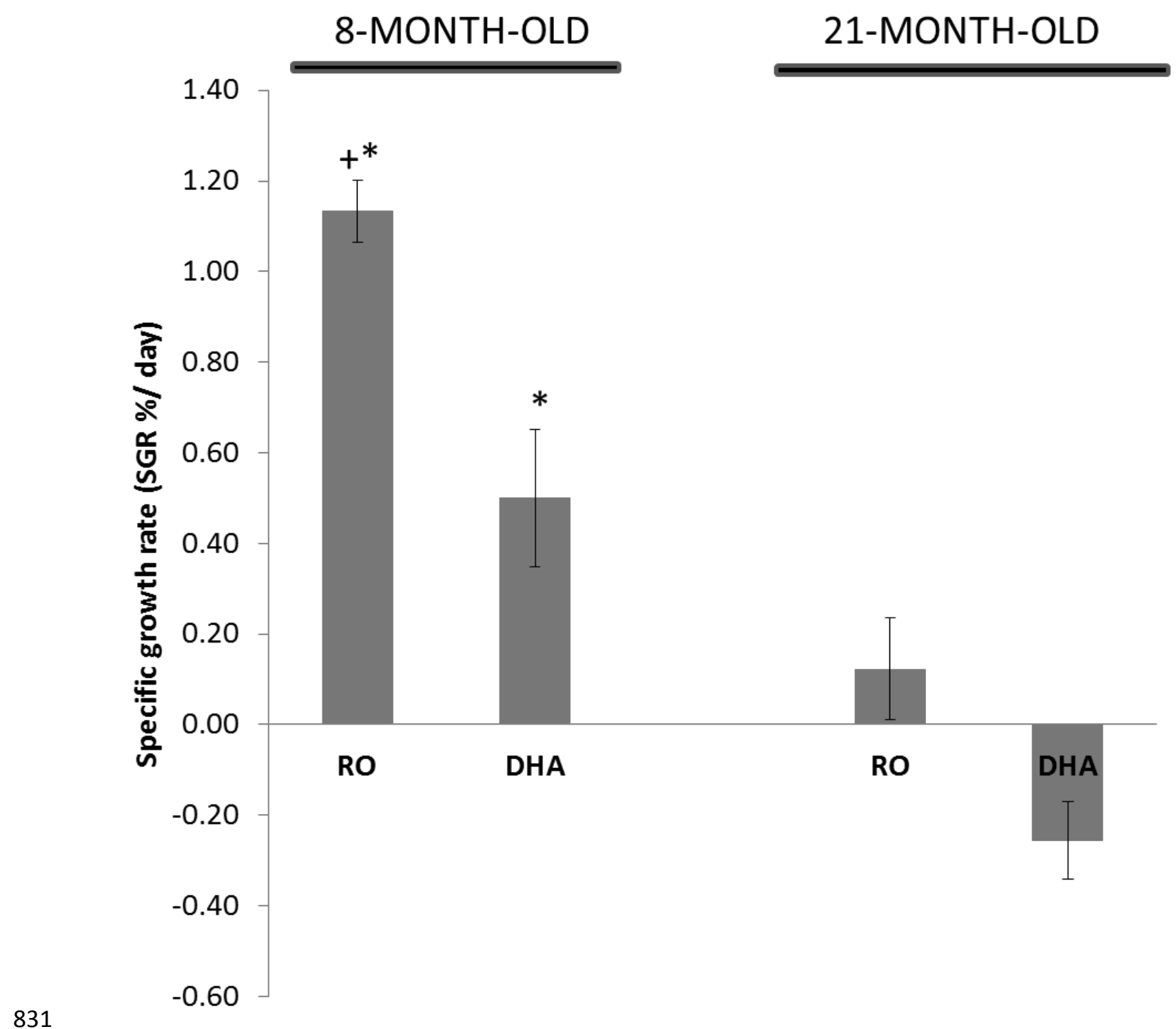

832 
$833 \quad$ Fig. 2

\section{8-MONTH-OLD}
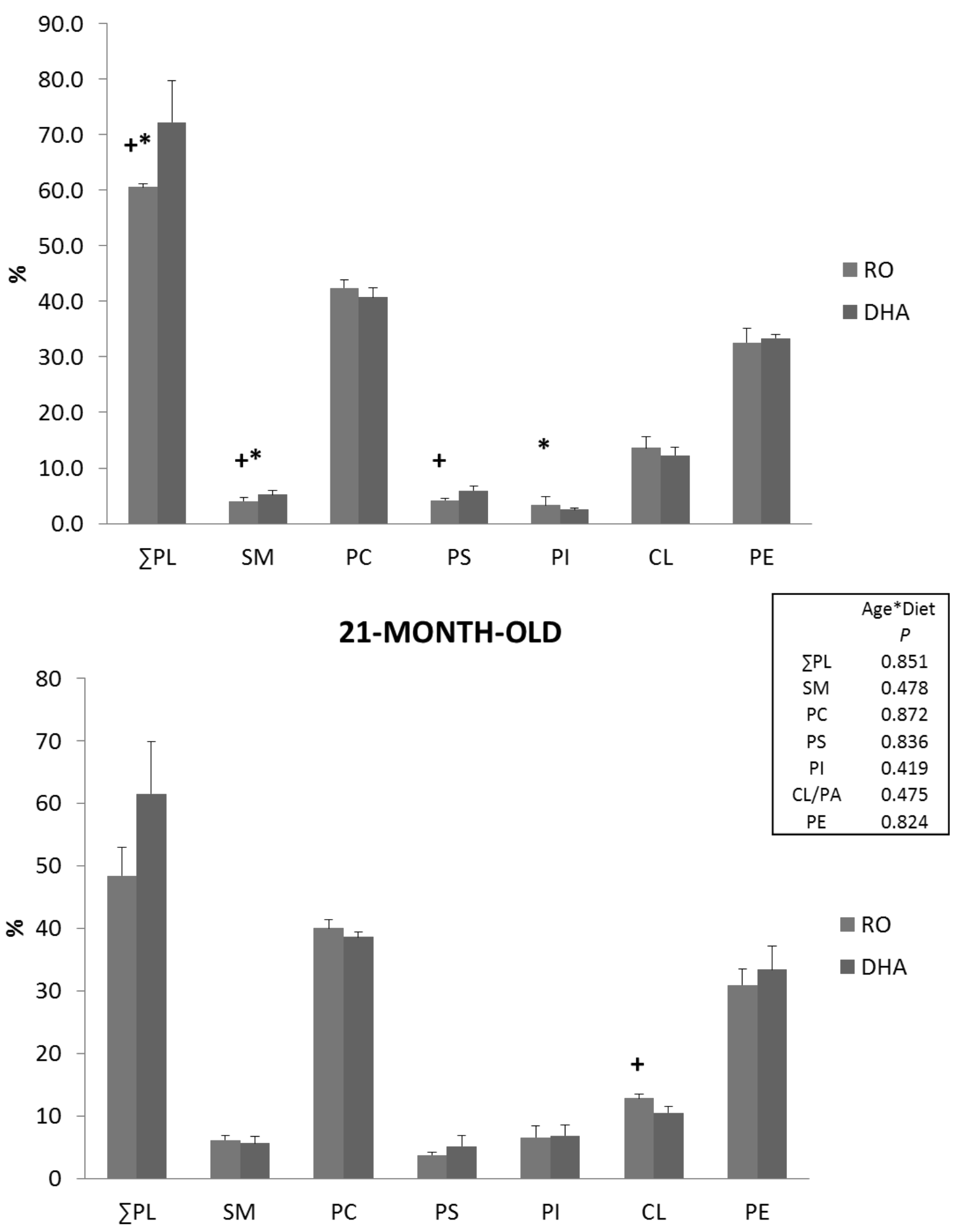
Fig.3

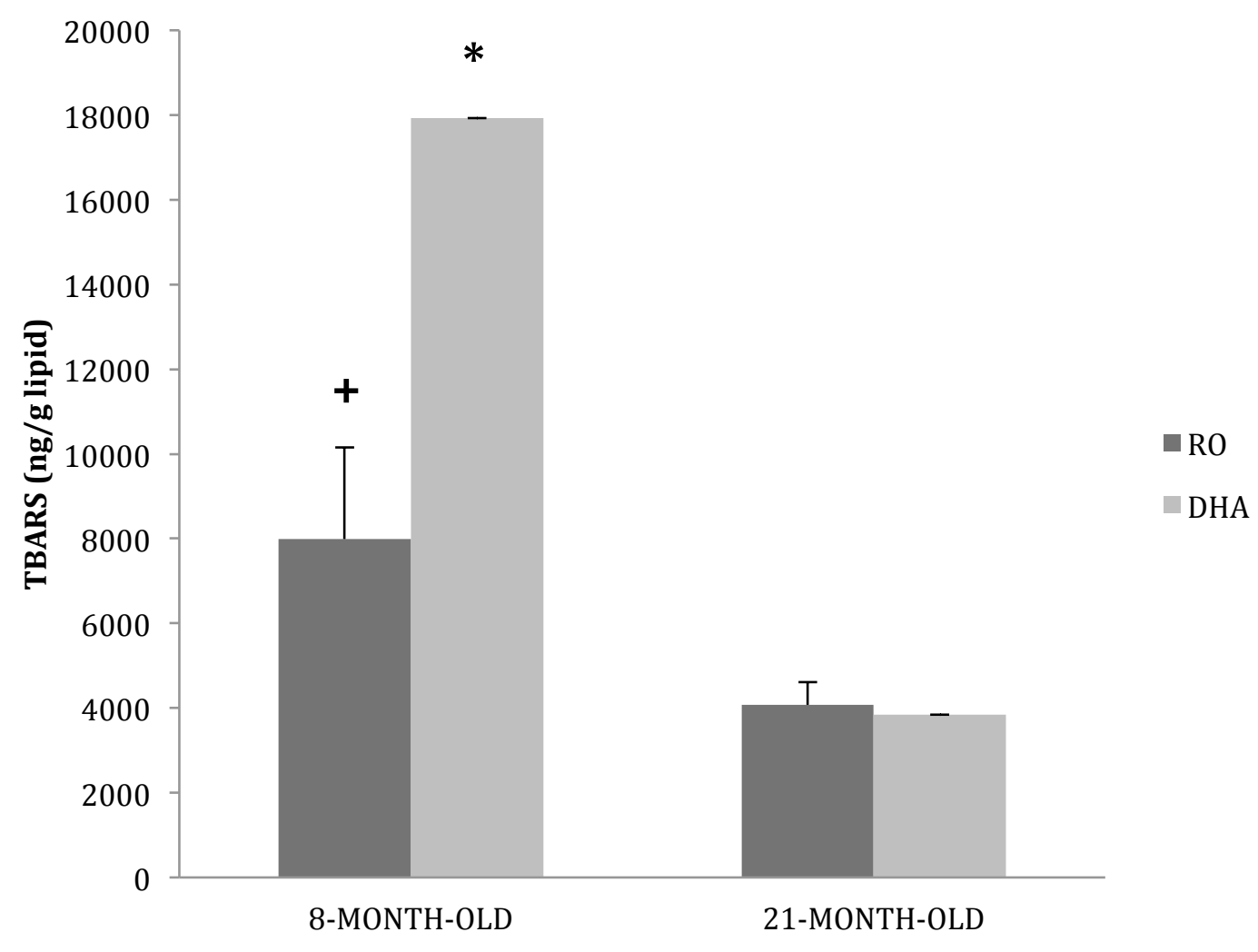


$838 \quad$ Fig.4

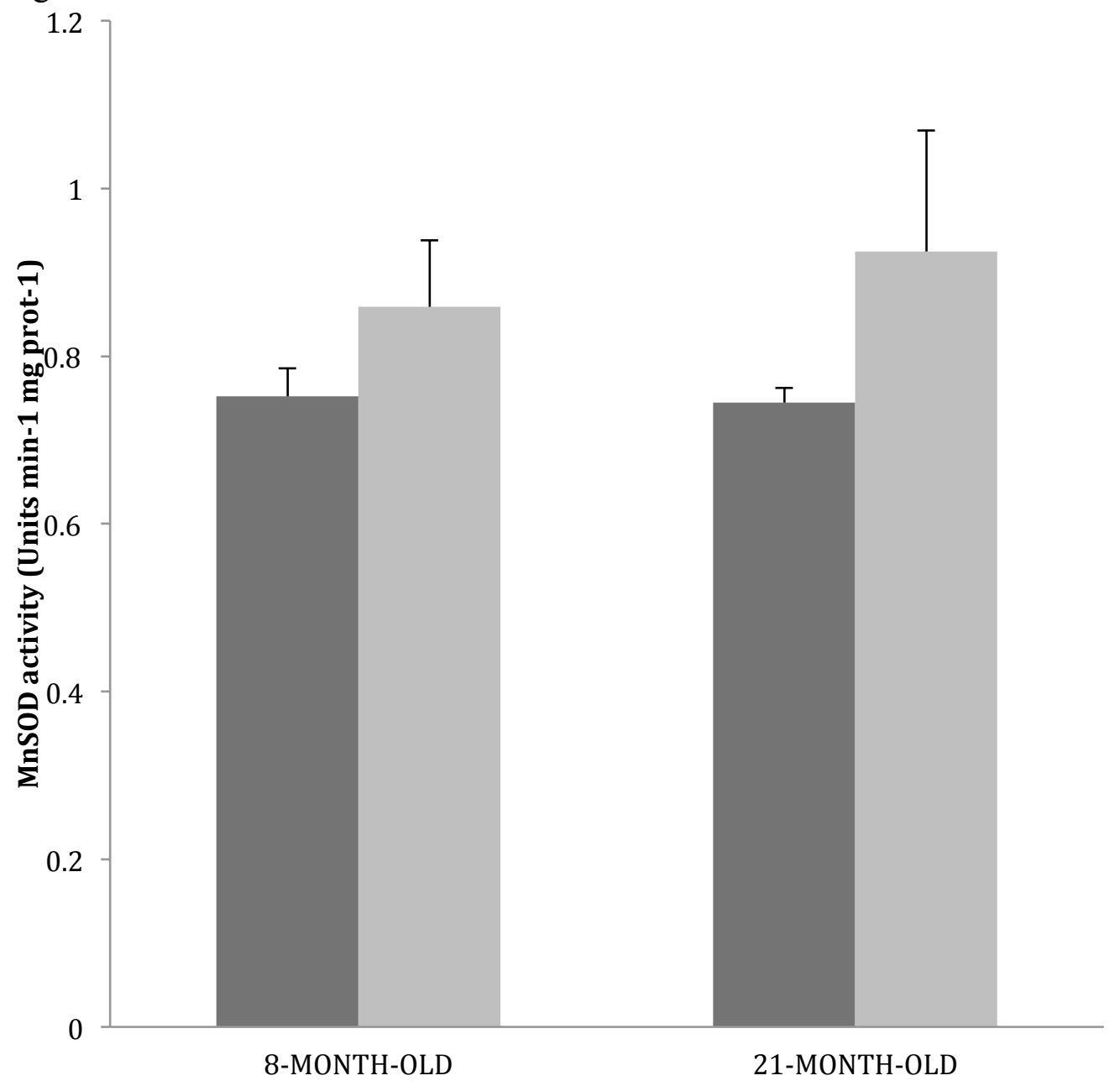

RO

$\square$ DHA

839 


\section{MUSCLE}

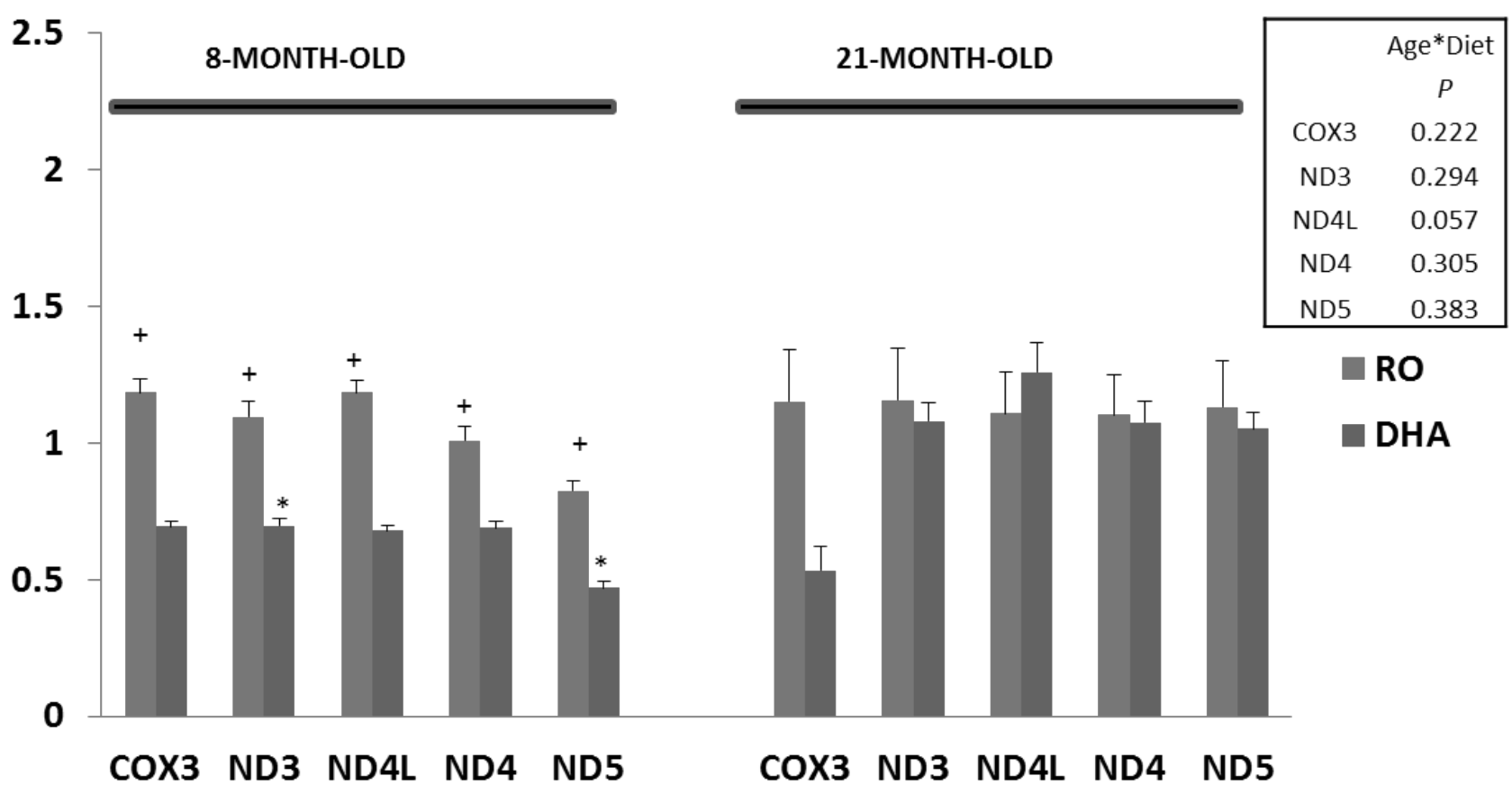

\section{LIVER}
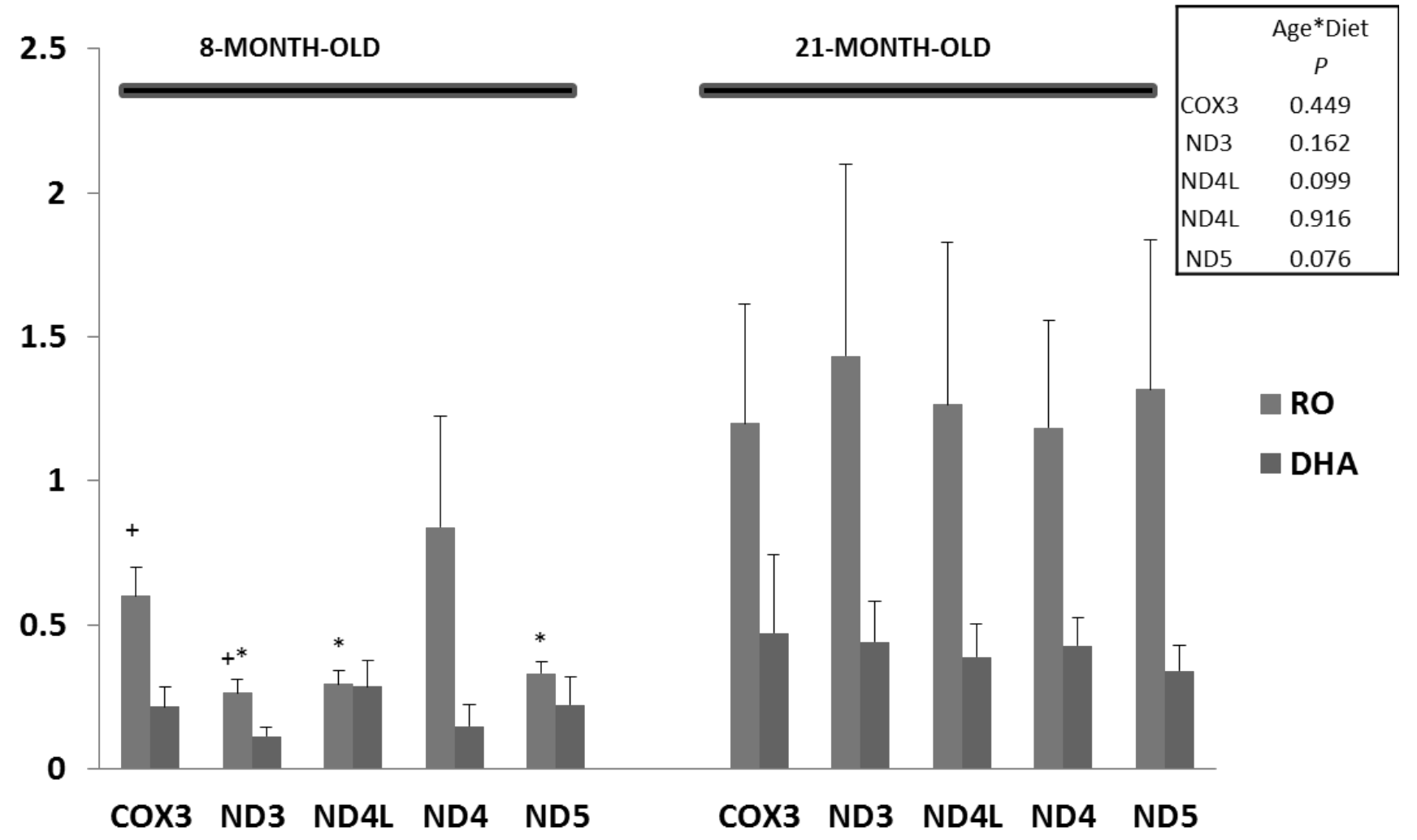
